\title{
Palliative Treatment of Colorectal Cancer with Secondary Metastasis Resection in Germany - Impact of the Multidisciplinary Treatment Approach on Prognosis and Cost: The Northern Bavaria IVOPAK I Project
}

\author{
Axel Wein $^{a} \quad$ Martin Emmert $^{\mathrm{b}} \quad$ Susanne Merkel ${ }^{\mathrm{c}}$ \\ Hanns-Detlev Harich $^{f}$ Juergen Siebler ${ }^{a}$ Roland Thiemann ${ }^{9}$ \\ Christof Lamberti $^{\text {h }}$ Bernhard Göttler ${ }^{i}$ Stefan Fries $^{j} \quad$ Alexander Kiani $^{k}$ \\ Rudolf Schlagl Marcus Grüner ${ }^{m}$ Simone Steinbild ${ }^{\text {e }}$ Sonja Eberld \\ Katharina Pohl-Dernick ${ }^{b}$ Frank Dörje $^{d}$ Thomas Horbach $^{n}$ \\ Oliver Schöffski ${ }^{b}$ Markus F. Neurath ${ }^{a}$ Werner Hohenberger ${ }^{c}$ \\ a Department of Internal Medicine 1 - Gastroenterology, Pneumology and Endocrinology, \\ Friedrich Alexander University of Erlangen-Nuremberg, ${ }^{b}$ Department of Health \\ Management, Friedrich Alexander University of Erlangen-Nuremberg, ${ }^{\circ}$ Department of \\ Surgery, Friedrich Alexander University of Erlangen-Nuremberg, and 'Pharmacy Department, \\ Friedrich Alexander University of Erlangen-Nuremberg, Erlangen, e Ambulatory Healthcare \\ Centre, Martha Maria Hospital, Nuremberg, ${ }^{f}$ Practice of Oncology, Hof, gPractice of \\ Oncology, Forchheim, ${ }^{\mathrm{h}}$ Ambulatory Healthcare Centre, Coburg Hospital, Coburg, ${ }^{\text {i }}$ Practice of \\ Oncology, Muhr am See, ${ }^{j}$ Ambulatory Healthcare Centre, Bamberg Hospital, Bamberg, \\ ${ }^{k}$ Ambulatory Healthcare Centre, Bayreuth Hospital, Bayreuth, 'Practice of Oncology, \\ Würzburg, m Practice of Oncology, Weiden, and n'Department of Surgery, Schwabach Hospital, \\ Schwabach, Germany
}

\section{Key Words}

Colorectal cancer · Palliative treatment results · Costs · Interdisciplinary cooperation

\begin{abstract}
Purpose: The aim of this study was to evaluate the quality of care and interdisciplinary cooperation in the palliative treatment of colorectal cancer (CRC), including the associated costs. Patients and Methods: 103 patients were enrolled from 13 institutions to reflect the existing clinical treatment reality and costs of palliative CRC treatment. We present the clinical outcome of the patients and compare the results obtained in the 3 centers with double-figure recruitment numbers (centers A, B, and C). Results: First-line treatment with 5-fluorouracil monotherapy was applied in exceptional cases. The regular treatment method comprised ei-
\end{abstract}




\section{Oncology}

\begin{tabular}{l|l}
\hline Oncology 2015;88:103-121 \\
\hline DOI: $10.1159 / 000368246$ & $\begin{array}{l}\text { @ 2014 S. Karger AG, Basel } \\
\text { www.karger.com/ocl }\end{array}$ \\
\hline
\end{tabular}

Wein et al.: Palliative Treatment of Colorectal Cancer with Secondary Metastasis Resection in Germany

ther an irinotecan- (30\%) or an oxaliplatin-based regimen (32\%). Biological agents were added to the treatment of 33 patients (32\%). The median overall survival (OS) of the total patient collective was 25 months. The OS differed significantly in 2 out of the 3 centers, ranging between 27 and 11 months. Secondary metastasis resections were performed in $26 \%$ of the total patient collective. The center with the most favorable outcome results also had the lowest costs for palliative treatment and care, including the lowest drug costs. Conclusion: A combined chemotherapy treatment was the rule. Concerning biological agents, a significant lack of their application in first-line treatment and the quality of interdisciplinary cooperation have to be addressed.

(C) 2014 S. Karger AG, Basel

\section{Introduction}

Colorectal cancer (CRC) is the second most common form of cancer in women and the third most common cancer in men: in 2008, the estimated worldwide incidence of CRC exceeded 1.2 million with a mortality rate of over 600,000 [1]. In Germany, CRC is one of the most common malignancies: more than 70,000 new cases and approximately 30,000 mortalities are recorded each year [2]. Metastasis at diagnosis is seen in about $20-25 \%$ of all CRCs $[2,3]$. Although recent studies have demonstrated substantial improvements in overall survival (OS) owing to the inclusion of new agents in palliative medicine treatment approaches [4-7] and close interdisciplinary cooperation with the objective of secondary metastatic resection [8], CRC still poses a major problem in terms of healthcare policy and economics [9].

The first version of the Interdisciplinary German S3 Guidelines for Diagnostics, Treatment and Follow-Up in CRC was published in 2004, with the objective of ensuring optimal care for all those affected [2]. The IVOPAK (Integrated Care and Quality Control in Palliative Treatment of CRC) I study prospectively recorded both the results of palliative treatment of CRC as well as the costs thereof in terms of healthcare economics. Therefore, it reflects the current reality of palliative CRC treatment. Furthermore, the study demonstrates the extent to which the guidelines have been implemented across Northern Bavaria. Therapeutic procedures for palliative CRC treatment vary widely. The respective individual case should be presented to an interdisciplinary tumor board prior to the treatment initiation in order to define the potential therapeutic options [2].

In the case of histologically proven distant metastases in the lungs or liver, the current CRC S3 guidelines published in 2008 recommend thoroughly different treatment options for primarily resectable liver and/or pulmonary metastases than they do for distant metastases in a palliative setting [2]. If resectable pulmonary metastases are observed, curative metastasis resection should be undertaken [2]. Patients should be presented to specialized centers, where proven experts have experience with surgical oncology procedures [2]. If primarily R0 resectable liver metastases are detected, curative resection is equally recommended. The feasibility of this surgical procedure should be judged in advance by an experienced surgeon [2]. In justified exceptional cases, neoadjuvant systemic treatment options might be considered $[2,10]$. Definitively nonresectable distant metastases represent a different situation: if primarily nonresectable liver metastases are observed, a systemic treatment should be started [2]. In such cases, regular evaluations to assess the potential resectability of secondary metastases are of utmost importance $[2,8,11]$.

Prior to and shortly after the publication of the 2008 guidelines, targeted therapeutics (i.e. biological agents) were shown to result in incremental improvements in palliative treatment, thus offering new therapeutic options for first-line treatment [4-7]. In several clinical studies, numerous inclusion and exclusion criteria amount to specific patient selec- 


\section{Oncology}

\begin{tabular}{|c|c|c|}
\hline \multicolumn{3}{|l|}{ Oncology 2015;88:103-121 } \\
\hline DOI: $10.1159 / 000368246$ & \multicolumn{2}{|c|}{$\begin{array}{l}\text { (c) } 2014 \text { S. Karger AG, Basel } \\
\text { www.karger.com/ocl }\end{array}$} \\
\hline \multicolumn{3}{|c|}{$\begin{array}{l}\text { Wein et al.: Palliative Treatment of Colorectal Cancer with Secondary Metastasis } \\
\text { Resection in Germany }\end{array}$} \\
\hline \multicolumn{2}{|c|}{ Multiple distant metastases in more than one organ } & and/or \\
\hline \multicolumn{3}{|c|}{$\begin{array}{l}\text { Diffuse bilateral metastatic infiltration within a single } \\
\text { organ (e.g. liver: invasion of the left and right branches } \\
\text { of the hepatic artery or the portal vein, or of the three } \\
\text { main branches of the hepatic vein) }\end{array}$} \\
\hline
\end{tabular}

Table 1. Definition of primarily nonresectable distant metastases in CRC by the interdisciplinary tumor board of the Erlangen University Hospital

(1)

tion. The results they generate, particularly the positive results, thus frequently do not reflect real treatment settings in daily clinical routine.

The objective of the observational IVOPAK study was to prospectively record the real treatment setting in daily clinical routine and to assess and discuss the implementation of the current $\mathrm{S} 3$ guidelines in palliative treatment strategies. In the context of integrated healthcare strategies, the aspect of interdisciplinary cooperation - in terms of both secondary metastasis resection and treatment costs - was also considered and evaluated.

\section{Patients and Methods}

\section{Eligibility Criteria}

The study was approved by the local ethics committee and met the standards laid down in the Helsinki Declaration of 1975 (in its current, revised form). Prior to the enrollment, written informed consent was obtained from all patients. Patients meeting the following inclusion criteria were eligible for enrollment in the study:

(1) diagnosis of histologically confirmed adenocarcinoma of the colon or rectum;

(2) Eastern Cooperative Oncology Group (ECOG) index $\leq 2$;

(3) definitively nonresectable metastases according to the decision of the respective oncological center, normally after presentation to the Erlangen University interdisciplinary tumor board (see definition of nonresectable metastases in metastatic CRC, table 1);

(4) palliative chemonaive patients, and

(5) members of a specific statutory health insurance scheme (AOK Bayern).

\section{Treatment}

The complete procedure of palliative and supportive treatment, including the interdisciplinary cooperation involved in CRC therapy, was performed in accordance with the principles of each ambulatory oncological center, without any specific precepts or standards stipulated by the project leaders. Only the results, i.e. overall response rate (ORR), OS, progression-free survival (PFS), secondary metastasis resection and toxicity according to the National Cancer Institute of Common Toxicity Criteria (NCI-CTC) were evaluated and calculated. The costs of treatment and palliative care in German real-world settings were evaluated over the 2-year period following the onset of palliative chemotherapy [9] from the perspective of the German statutory health insurance.

\section{Statistics}

The Kaplan-Meier method was used to calculate OS and PFS. OS was defined as the time interval from the onset of palliative chemotherapy to death from any cause. The response was assessed according to the Response Evaluation Criteria in Solid Tumors (RECIST) version 1.0 [12]. At each treatment cycle, patients underwent clinical examination and laboratory assessment. Adverse events (according to the NCI-CTC version 2.0) and concomitant medication were recorded [13]. PFS was defined as the time from the start of palliative chemotherapy to the first radiological or clinical observation of disease progression, or death from any cause. All variables were summarized by descriptive statistics. The $95 \%$ confidence intervals (CIs) were calculated in accordance with the Greenwood criteria [14]. 


\section{Oncology}

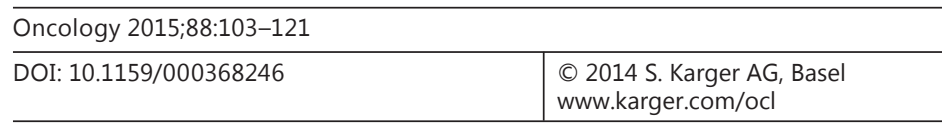

Wein et al.: Palliative Treatment of Colorectal Cancer with Secondary Metastasis Resection in Germany

Table 2. Patient characteristics

\begin{tabular}{|c|c|c|c|c|c|}
\hline & $\begin{array}{l}\text { Total cohort } \\
(n=103)\end{array}$ & $\begin{array}{l}\text { Center A } \\
(n=37)\end{array}$ & $\begin{array}{l}\text { Center B } \\
(n=35)\end{array}$ & $\begin{array}{l}\text { Center C } \\
(n=10)\end{array}$ & $\mathrm{p}$ \\
\hline $\begin{array}{l}\text { Age (max/median/min), years } \\
\text { Gender }\end{array}$ & $87 / 70 / 20$ & $87 / 70 / 22$ & $80 / 69 / 37$ & $79 / 73.5 / 42$ & 0.447 \\
\hline Male & $68(66)$ & $24(66)$ & $21(60)$ & $7(70)$ & 0.853 \\
\hline Female & $35(34)$ & $13(34)$ & $14(40)$ & $3(30)$ & \\
\hline \multicolumn{6}{|l|}{ Primary tumor location } \\
\hline Colon & $57(55)$ & $20(55)$ & $26(73)$ & $3(30)$ & 0.033 \\
\hline Rectum & $46(45)$ & $17(45)$ & $9(27)$ & $7(70)$ & \\
\hline \multicolumn{6}{|l|}{ Metastases } \\
\hline Synchronous & $50(49)$ & $14(38)$ & $19(54)$ & $8(80)$ & 0.058 \\
\hline Metachronous & $53(51)$ & $23(62)$ & $16(46)$ & $2(20)$ & \\
\hline \multicolumn{6}{|l|}{ Liver-only metastases? } \\
\hline Yes & $55(53)$ & $19(51)$ & $19(55)$ & $6(60)$ & 0.908 \\
\hline No & $48(47)$ & $18(49)$ & $16(46)$ & $4(40)$ & \\
\hline \multicolumn{6}{|l|}{ ECOG grade } \\
\hline $0 / 1$ & 90 (87) & $32(86)$ & $30(86)$ & $9(90)$ & 1.0 \\
\hline 2 & $13(13)$ & $5(14)$ & $5(14)$ & $1(10)$ & \\
\hline
\end{tabular}

Figures represent patient numbers with percentages in parentheses unless otherwise indicated.

\section{Results}

A total of 103 patients met the inclusion criteria and were enrolled in the study between February 2006 and November 2011. November 30, 2011 was defined as the cutoff date for the evaluation of patient data. A further 2 patients $(2 \%)$ were defined as ineligible: 1 patient withdrew informed consent and 1 patient had the wrong statutory health insurance. Median follow-up was 23 months (range: 0-77). At the cutoff date, 93 out of the 103 patients (90\%) had died and 10 patients (9\%) showed no evidence of disease (NED).

\section{Patient Characteristics}

The main patient characteristics - both in terms of the total patient collective and subcategorized into the patients at the centers $\mathrm{A}, \mathrm{B}$ and $\mathrm{C}$ - are represented in table 2 . The characteristics of patients treated at these 3 centers were comparable (table 2). The details of the regimens applied in first-line treatment and the frequency of their application, for both the entire patient cohort and subcategorized into the patients treated at the centers A, B and C, are shown in table 7.

\section{Multidisciplinary Cooperation}

Presentation prior to Palliative Treatment

The presentation of the patients to the interdisciplinary tumor board prior to the onset of palliative treatment was as follows: total number 53/103 (51\%), center A $37 / 37$ (100\%), center B 9/35 (26\%) and center C 2/10 (20\%) ( $\chi^{2}$ test: $\left.\mathrm{p}<0.001\right)$.

Secondary Metastasis Resection after Downsizing by Means of First-Line Treatment

The evaluation was performed for all cases in which an attempt to achieve a curative situation was undertaken and also for the patients with peritonectomy plus hyperthermic 


\section{Oncology}

\begin{tabular}{l|l}
\hline Oncology 2015;88:103-121 \\
\hline DOI: $10.1159 / 000368246$ & $\begin{array}{l}\text { @ 2014 S. Karger AG, Basel } \\
\text { www.karger.com/ocl }\end{array}$ \\
\hline
\end{tabular}

Wein et al.: Palliative Treatment of Colorectal Cancer with Secondary Metastasis Resection in Germany

Table 3. Maximum toxicity experienced by all patients $(n=103)$ participating in the IVOPAK project

\begin{tabular}{|c|c|c|c|c|c|}
\hline & \multicolumn{5}{|c|}{ Toxicity grade } \\
\hline & 0 & 1 & 2 & 3 & 4 \\
\hline Anemia & $93(90)$ & $5(5)$ & $4(4)$ & $1(1)$ & - \\
\hline Leukocytopenia & $76(73)$ & $14(14)$ & $10(10)$ & $3(3)$ & - \\
\hline Neutropenia & $92(89)$ & $6(6)$ & $5(5)$ & - & - \\
\hline Thrombocytopenia & $95(92)$ & $2(2)$ & $4(4)$ & $2(2)$ & - \\
\hline Stomatitis & $100(97)$ & $1(1)$ & - & $2(2)$ & - \\
\hline Nausea & $60(58)$ & $26(25)$ & $14(14)$ & $3(3)$ & - \\
\hline Vomiting & $78(75)$ & $13(13)$ & $9(9)$ & $2(2)$ & $1(1)$ \\
\hline Diarrhea & $53(51)$ & $9(9)$ & $28(27)$ & $11(11)$ & $2(2)$ \\
\hline Hand-foot syndrome & $89(86)$ & $5(5)$ & $6(6)$ & $3(3)$ & - \\
\hline Alopecia & $84(81)$ & $9(9)$ & $10(9)$ & & \\
\hline Peripheral sensory neuropathy & $92(89)$ & $5(5)$ & $6(6)$ & - & - \\
\hline Hypertonia & $99(96)$ & $1(1)$ & $1(1)$ & $2(2)$ & - \\
\hline Dermatitis acneiform & $97(94)$ & $3(3)$ & $3(3)$ & - & - \\
\hline
\end{tabular}

Figures represent patient numbers with percentages in parentheses. Toxicity is graded according to the NCI-CTC.

intraperitoneal chemotherapy or radiofrequency ablation, regardless of the residual tumor classification. Results are shown in table 7. In a further 8 out of 13 centers (61\%) with a total of 10 enrolled patients (9\%), neither presentation to the interdisciplinary tumor board (prior to the onset of first-line treatment) nor secondary metastasis resections were performed.

Patient Group with Secondary Metastasis Resections ( $\mathrm{n}=27)$

Of the patients with secondary metastasis resections, 21 out of 27 (77\%) had liver-only metastases and $2 / 27$ patients (7\%) had lung-only metastases. In 4 out of 27 patients (14\%), a combination of liver and lung or liver and peritoneal metastases was observed. Of the 27 patients with secondary resections, 22 (81\%) were described as having undergone R0 resection; 10 of these $22 \mathrm{R} 0$ resected patients (45\%) had NED at the cutoff date, which equates to $40 \%(10 / 27)$ of all patients with secondary metastasis resections. Recurrence and subsequent death from progressive disease was observed in 15 of the 27 resected patients (55\%).

\section{Toxicity in First-Line Treatment}

The symptoms of toxicity experienced by the 103 patients during first-line treatment are listed in table 3. Gastrointestinal side effects, in particular severe diarrhea (CTC grade 3/4) predominated in 13 patients (13\%; 95\% CI: 6.2-19.0); severe nausea and vomiting were observed in 6 patients (6\%; 95\% Cl: 0.7-9.0). Severe hematological toxicity (CTC grade $3 / 4$ ) was rare, with leukocytopenia being observed in 3 patients (3\%; 95\% CI: 0-6.2; table 3). Treatment-induced deaths did not occur. Toxicity did not vary significantly between the centers A, B and C (data not shown), whereby low-grade toxicity in the form of dermatitis acneiform was observed at the center using cetuximab in first-line treatment.

\section{Overall Survival}

OS in the total patient collective ( $\mathrm{n}=103)$ was 25 months (95\% CI: 21-29; fig. 1). Restricted to the centers A, B and C, OS times were 27 (95\% CI: 23-32), 25 (95\% CI: 17-33) and 11 months (95\% CI: 0-24) for centers A, B and C, respectively. OS differed significantly between 


\section{Oncology}

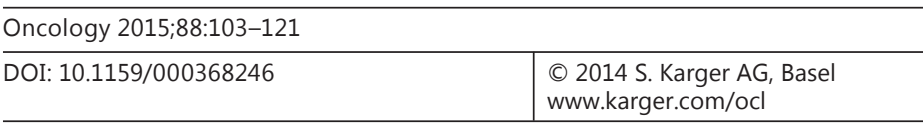

Wein et al.: Palliative Treatment of Colorectal Cancer with Secondary Metastasis Resection in Germany

Fig. 1. Median OS: IVOPAK total patient collective $(\mathrm{n}=103): 25$ months (95\% Cl: 21-29 months). 2-year OS 52.2\%; 3-year OS $30.7 \%$; 5-year OS $14.5 \%$.

Fig. 2. Median OS: patients of the 3 study centers with double-figure recruitment numbers: center A ( $\mathrm{n}=37) 27$ months (95\% Cl: $23-$ 32 months); center B ( $\mathrm{n}=35) 25$ months (95\% Cl: 17-33 months); center C $(\mathrm{n}=10) 11$ months $(95 \%$ Cl: 0-24 months). 2-year OS 68/ 51/20\%; 3-year OS 34/34/20\%; 5 -year OS $30 / 10 / 0 \%$. p porall $=$ $0.013 ; \mathrm{p}_{\mathrm{A} \text { vs. } \mathrm{B}}=0.214 ; \mathrm{p}_{\mathrm{A} \text { vs. } \mathrm{C}}=$ $0.006 ; \mathrm{p}_{\text {B vs. } \mathrm{C}}=0.036$.
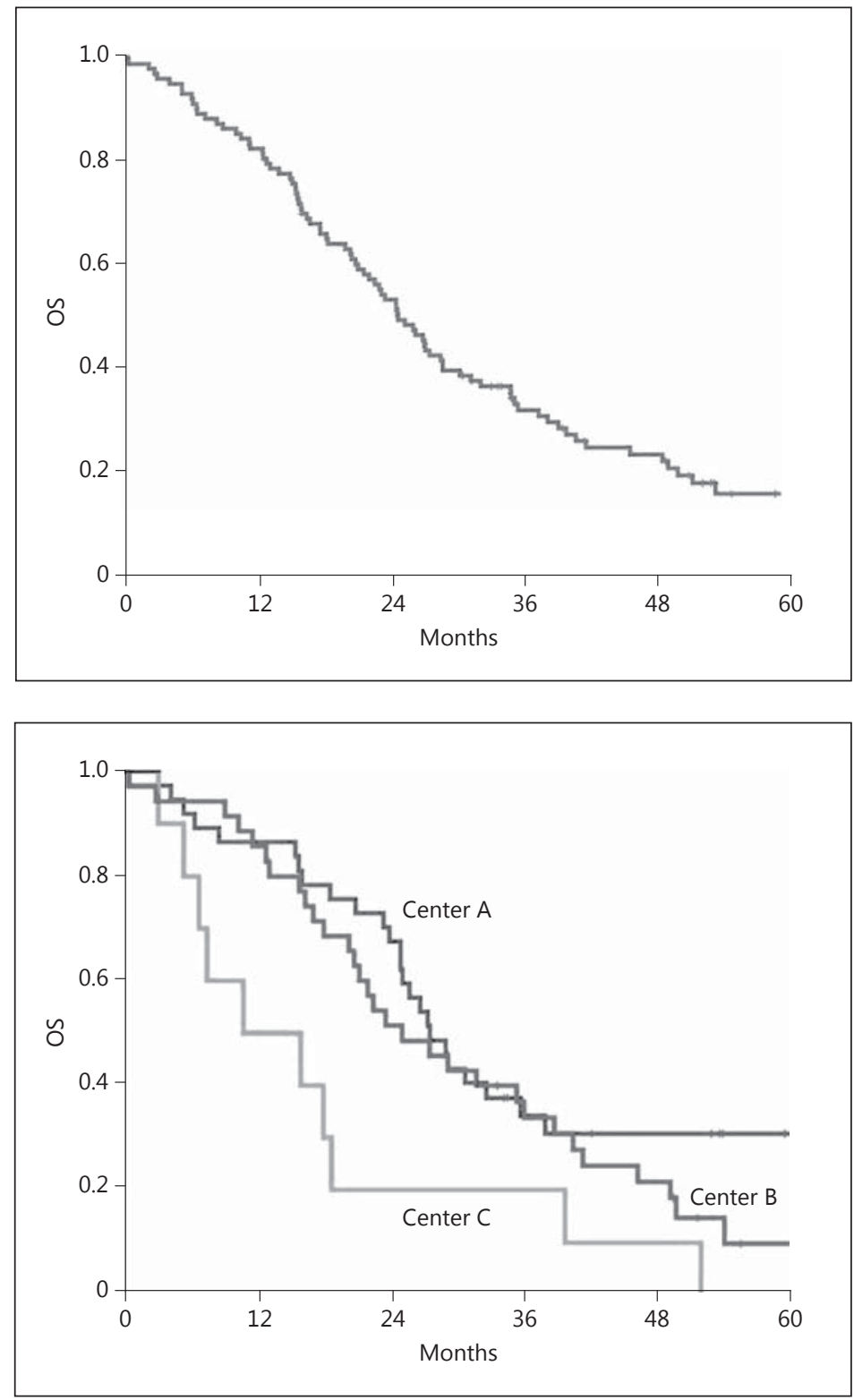

centers $\mathrm{A}$ and $\mathrm{C}(\mathrm{p}=0.006$; fig. 2$)$. When the $\mathrm{OS}$ of the patient group treated with a multimodal strategy (i.e. secondary metastasis resection after first-line treatment; $\mathrm{n}=27$; multimodal group) is compared to the OS of the patient group treated solely with sequential chemotherapy ( $\mathrm{n}=76$; palliative group), highly significant differences $(\mathrm{p}<0.001)$ were observed: OS times of 49 months (95\% CI: 31-67) were achieved in the multimodal group compared to 22 months (95\% CI: 17-27) in the palliative group (fig. 3).

\section{Progression-Free Survival}

The median PFS following first-line treatment was 7 months (95\% CI: 5-9) for the total patient collective $(n=103)$ as shown in figure 4 . In the centers A, B and C, PFS rates amounted to 10 months (95\% CI: 6-14), 8 months (95\% CI: 4-12) and 4 months (95\% CI: $3-4$ ), respectively. A significant difference in PFS is apparent between centers A and C ( $p=0.001$; fig. 5). 


\section{Oncology}

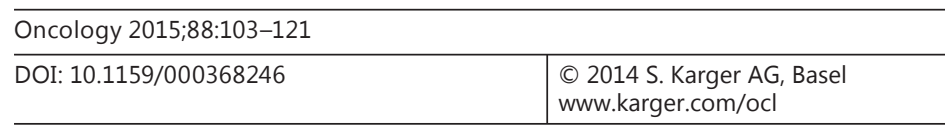

Fig. 3. Median OS: multimodal patient group (first-line treatment plus secondary metastasis resection) versus palliative patient group (sequential treatment): multimodal patient group ( $\mathrm{n}=$ 27) 49 months (95\% Cl: 31-67 months) and palliative patient group ( $=76) 22$ months (95\% Cl: 17-27 months). 2-year OS 78/43\%; 3-year OS 63/19\%; 5 -year OS 46/0\%. p < 0.001 .

Wein et al.: Palliative Treatment of Colorectal Cancer with Secondary Metastasis Resection in Germany

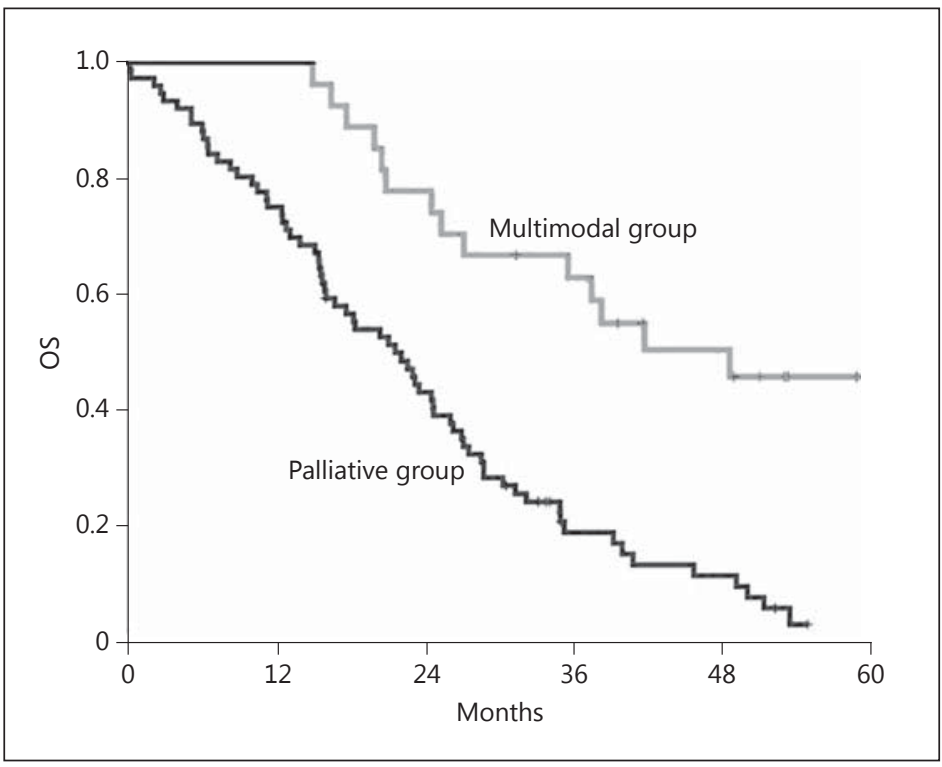

Fig. 4. Median PFS: total patient collective $(\mathrm{n}=103): 7$ months (95\% Cl: 5-9 months). 1-year PFS 32\%; 2-year PFS 15\%.

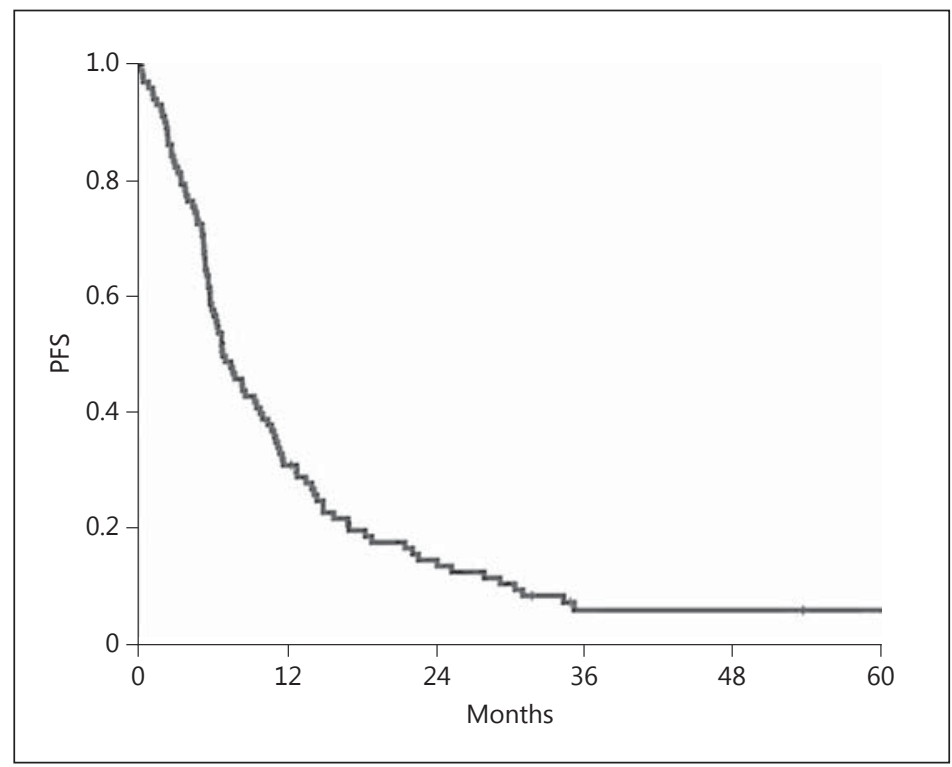

When the median PFS of the group of patients who underwent secondary metastasis resection after first-line treatment ( $\mathrm{n}=27$; multimodal group) is compared with the group of patients who had received a treatment based solely on sequential chemotherapy $(n=76$; palliative group), the difference in PFS is highly significant $(\mathrm{p}<0.001)$ and in favor of the multimodal patient group: 18 months (95\% CI: 8-29) versus 6 months (95\% CI: 5-7; fig. 6).

\section{Treatment Costs}

The total costs of palliative CRC treatment and care in the IVOPAK project have been evaluated and published previously [9]. Costs for drugs - such as cytostatic agents, biologicals and biomodulators - represent the main cost drivers and constitute $70 \%$ of the total costs [9]. In the centers $\mathrm{A}, \mathrm{B}$ and $\mathrm{C}$, drug costs constitute the main factor contributing to the total cost of palliative care during the first and second years of treatment (table 4). The differences in 


\section{Oncology}

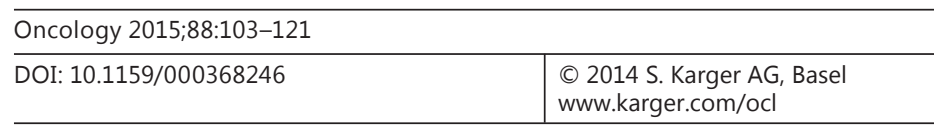

Wein et al.: Palliative Treatment of Colorectal Cancer with Secondary Metastasis Resection in Germany

Fig. 5. Median PFS: patients of the 3 study centers with doublefigure recruitment numbers: center A 10 months (95\% Cl: 6-14 months); center B 8 months ( $95 \%$ Cl: 4-12 months); center C 4 months (95\% Cl: 3-4 months). $\mathrm{p}_{\mathrm{A} \text { vs. } \mathrm{B}}=0.032 ; \mathrm{p}_{\mathrm{A} \text { vs. } \mathrm{C}}=0.001$; $\mathrm{p}_{\mathrm{B} \text { vs. C }}=0.098$.

Fig. 6. Median PFS: multimodal patient group (first-line treatment plus secondary metastasis resection) versus palliative patient group (sequential treatment): multimodal patient group ( $\mathrm{n}=27) 18$ months (95\% Cl: 8-29 months) and palliative patient group $(\mathrm{n}=76) 6$ months $(95 \% \mathrm{Cl}$ : 5-7 months). $\mathrm{p}<0.001$.
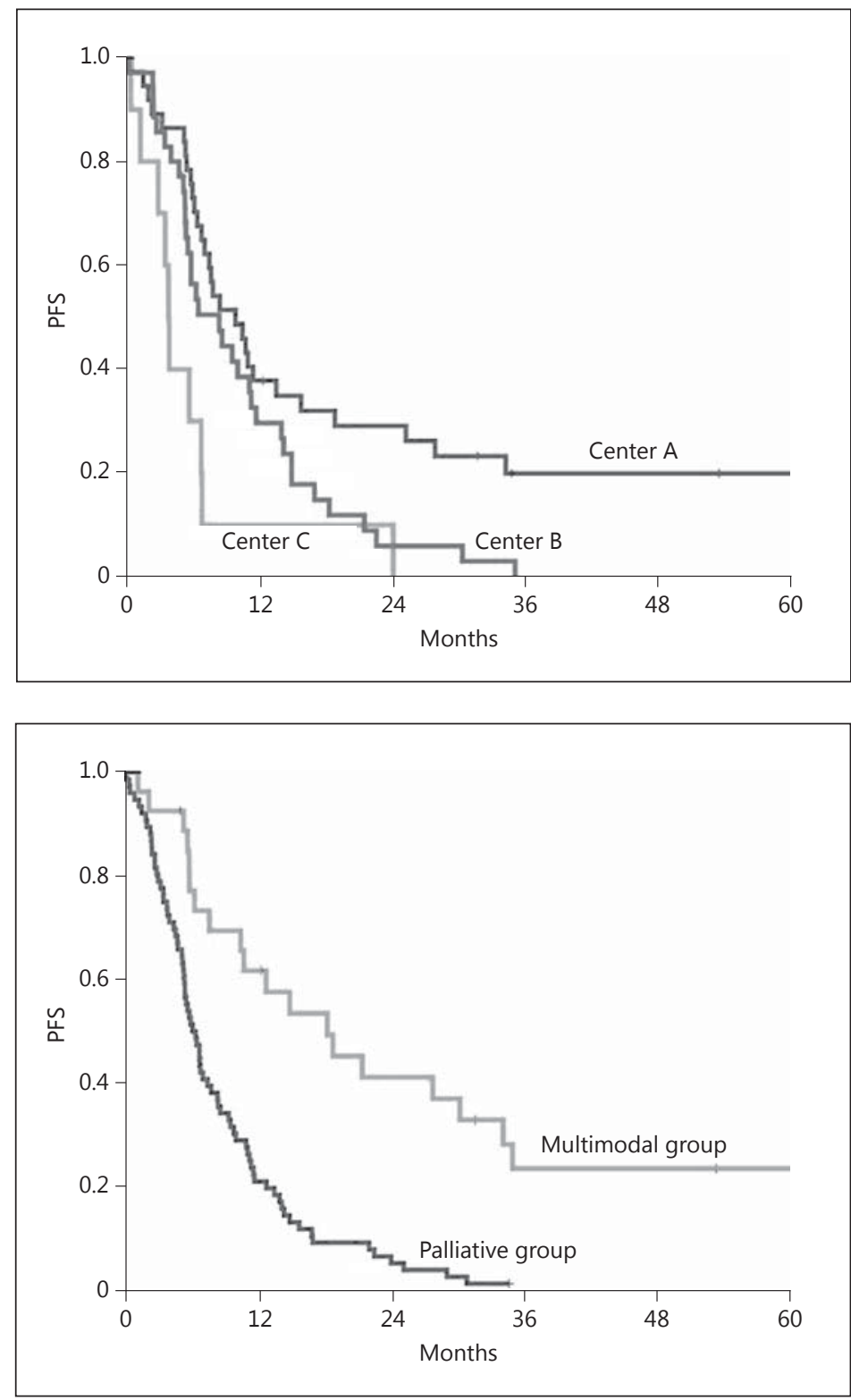

both total and drug costs were substantial between the abovementioned centers, particularly during the first year of palliative treatment (table 4). The differences in drug costs between the 3 centers with more than 10 enrolled patients, itemized in terms of individual drug costs, are presented in tables 5 and 6 . Drug costs vary significantly here too, not only during the first year of treatment but also during the second year. Possible causes and reasons for this are outlined in the discussion section.

\section{Response}

The ORR, i.e. partial remission (PR) plus complete remission (CR), to first-line treatment was 38\% ( $\mathrm{n}=39$ ) for the total IVOPAK patient collective $(\mathrm{n}=103)$. PR accounted for $37 \%$ $(\mathrm{n}=38)$ and radiological CR (according to imaging techniques) was observed in 1 patient (1\%) after first-line treatment with the FOLFOX6 regimen. In a further 5 patients (5\%), CR was achieved after radiological PR according to imaging techniques plus subsequent second- 


\section{Oncology}

\begin{tabular}{l|l}
\hline Oncology 2015;88:103-121 \\
\hline DOI: 10.1159/000368246 & $\begin{array}{l}\text { @ 2014 S. Karger AG, Basel } \\
\text { www.karger.com/ocl }\end{array}$ \\
\hline
\end{tabular}

Wein et al.: Palliative Treatment of Colorectal Cancer with Secondary Metastasis Resection in Germany

Table 4. Total costs of palliative treatment and care at the 3 centers with double-figure recruitment numbers

\begin{tabular}{|c|c|c|c|c|c|c|c|c|}
\hline & \multicolumn{2}{|c|}{ Center A $(n=37)$} & \multicolumn{2}{|c|}{ Center B $(n=35)$} & \multicolumn{2}{|c|}{ Center C $(n=10)$} & \multicolumn{2}{|c|}{ Variance analysis, centers } \\
\hline & mean costs & SD & mean costs & SD & mean costs & S SD & $\begin{array}{l}A, B \text { and } C^{1} \\
p \text { value }\end{array}$ & $\begin{array}{l}A \text { and } B^{2} \\
p \text { value }\end{array}$ \\
\hline \multicolumn{9}{|l|}{ Average costs year 1} \\
\hline Transport costs & 545.66 & $1,759.78$ & 205.15 & 212.66 & 0.00 & 0.00 & 0.33112 & 0.26349 \\
\hline Inpatient services & $9,960.71$ & $2,677.04$ & $10,217.19$ & $2,501.13$ & $7,442.40$ & $2,898.91$ & 0.01395 & 0.68005 \\
\hline Preinpatient services & $1,261.31$ & 375.44 & $1,251.39$ & 392.79 & 886.58 & 440.04 & 0.02402 & 0.91428 \\
\hline Emergency services & 304.47 & 86.85 & 93.26 & 0.00 & 0.00 & 0.00 & 0.02235 & 0.02235 \\
\hline Outpatient services & 0.00 & 0.00 & $1,652.80$ & 880.48 & $1,144.82$ & 798.22 & 0.00000 & 0.00000 \\
\hline Other services & 0.00 & 0.00 & 7.92 & 22.80 & 0,00 & 0,00 & 0.07880 & 0.04767 \\
\hline Outpatient rehabilitation & 5.42 & 15.32 & 0.00 & 0.00 & 0.00 & 0.00 & 0.07156 & 0.04374 \\
\hline Inpatient rehabilitation & 237.96 & 820.76 & 10.58 & 62.57 & 0.00 & 0.00 & 0.19035 & 0.11133 \\
\hline Long-term and on-demand medication & 453.65 & 480.79 & 366.38 & 402.48 & 832.24 & $1,284.70$ & 0.16755 & 0.43234 \\
\hline Supportive medication & 391.82 & 285.48 & 448.94 & 150.14 & 503.74 & 920.12 & 0.79245 & 0.66545 \\
\hline Medical supplies & 108.29 & 170.15 & 0.00 & 0.00 & 6.19 & 7.34 & 0.00042 & 0.00053 \\
\hline $\begin{array}{l}\text { Cytostatic agents/biological } \\
\text { agents/biomodulators }\end{array}$ & $24,098.58$ & $13,504.53$ & $39,216.55$ & $27,302.16$ & $23,451.21$ & $20,039.15$ & 0.00821 & 0.00492 \\
\hline \multicolumn{9}{|l|}{ Average costs year 2} \\
\hline Transport costs & 35.26 & 58.09 & 189.23 & 210.56 & 156.60 & 0.00 & 0.00395 & 0.00186 \\
\hline Inpatient services & $7,303.94$ & $3,131.68$ & $6,812.58$ & $3,242.87$ & $5,511.59$ & $4,558.43$ & 0.63250 & 0.58830 \\
\hline Preinpatient services & $1,193.27$ & 546.63 & $1,115.72$ & 564.07 & 894.08 & 790.42 & 0.66201 & 0.62379 \\
\hline Emergency services & 249.94 & 106.74 & 0.00 & 0.00 & 279.78 & 0.00 & 0.78631 & - \\
\hline Outpatient services & 0.00 & 0.00 & $1,162.19$ & 826.69 & 0.00 & 0.00 & 0.00000 & 0.00000 \\
\hline Other services & 0.00 & 0.00 & 10.04 & 29.04 & 0.00 & 0.00 & 0.22820 & 0.10373 \\
\hline Outpatient rehabilitation & 3.80 & 18.98 & 3.96 & 19.38 & 0.00 & 0.00 & 0.97980 & 0.97709 \\
\hline Inpatient rehabilitation & 0.00 & 0.00 & 107.96 & 400.75 & 0.00 & 0.00 & 0.40345 & 0.19989 \\
\hline Long-term and on-demand medication & 369.73 & 444.06 & 286.76 & 307.82 & 502.33 & 374.55 & 0.57402 & 0.50565 \\
\hline Supportive medication & 358.07 & 263.04 & 103.91 & 0.00 & 551.56 & 541.72 & 0.38365 & 0.35877 \\
\hline Medical supplies & 23.52 & 102.54 & 0.00 & 0.00 & 0.00 & 0.00 & 0.54295 & 0.33056 \\
\hline $\begin{array}{l}\text { Cytostatic agents/biological } \\
\text { agents/biomodulators }\end{array}$ & $28,375.05$ & $21,117.36$ & $32,071.88$ & $27,284.08$ & $26,204.28$ & $17,344.98$ & 0.84182 & 0.63444 \\
\hline \multicolumn{9}{|l|}{$\varnothing \mathrm{OH}$} \\
\hline Total costs year 1 & $36,941.71$ & $15,129.99$ & $52,984.29$ & $28,883.11$ & $33,819.18$ & $24,119.03$ & 0.00707 & 0.00520 \\
\hline Total costs year 2 & $28,576.94$ & $24,422.46$ & $36,367.79$ & $31,688.33$ & $32,045.93$ & $23,535.12$ & 0.60112 & 0.31974 \\
\hline
\end{tabular}

Values represent euros. $\emptyset \mathrm{OH}=$ Overheads. ${ }^{1}$ Univariate ANOVA. ${ }^{2}$ Student's $t$ test/Welch's $\mathrm{t}$ test.

ary metastasis resection (multimodal procedure). Overall, the CR rate in the IVOPAK study reached $6 \%$. The best response observed among the 6 patients who had received 5 -fluorouracil (5-FU) monotherapy as the first-line treatment was a stable disease situation.

\section{Discussion}

In CRC, the treatment of histologically proven, primarily resectable distant liver and lung metastases differs distinctly from the treatment of distant metastases in a palliative situation $[2,15,16]$.

Numerous recent phase III studies on palliative first-line treatment have refrained from presenting a clear definition of nonresectable distant metastases of CRC as an inclusion criterion: the inclusion criteria 'histologically proven metastatic colorectal adenocarcinoma' [4] and 'untreated metastatic colorectal carcinoma' [17] do not definitively exclude patients with primarily resectable distant metastases from enrollment into these palliative first-line studies. The study conducted by Watkins et al. [16] confirms the resectability status as an important prognostic factor. Despite the same treatment regimen, i.e. XELOX, being applied in both groups of the latter study, the palliative patient collective (group A) had a median OS of 14.6 months, whereas this was 52.9 months in the patient group with primarily resectable distant metastases (group C) [16]. 


\section{Oncology}

\begin{tabular}{l|l}
\hline Oncology 2015;88:103-121 \\
\hline DOI: 10.1159/000368246 & $\begin{array}{l}\text { @ 2014 S. Karger AG, Basel } \\
\text { www.karger.com/ocl }\end{array}$ \\
\hline
\end{tabular}

Wein et al.: Palliative Treatment of Colorectal Cancer with Secondary Metastasis Resection in Germany

Table 5. Drug costs for palliative care at the 3 centers with double-figure recruitment numbers during the first year of treatment

\begin{tabular}{|c|c|c|c|c|c|c|c|c|c|c|c|c|c|}
\hline \multirow[t]{2}{*}{ Drug } & \multicolumn{4}{|c|}{ Center A (37 patients) } & \multicolumn{4}{|c|}{ Center B (35 patients) } & \multicolumn{4}{|c|}{ Center C (10 patients) } & \multirow{2}{*}{$\begin{array}{l}\mathrm{p} \\
\text { value }^{1}\end{array}$} \\
\hline & total & VAT & $\mathrm{n}$ & SD & total & VAT & $\mathrm{n}$ & SD & total & VAT & $\mathrm{n}$ & SD & \\
\hline 5-FU + folinic acid & $415,678.35$ & 560.21 & 742 & 103.51 & $323,193.74$ & 405.00 & 798 & 184.74 & $92,266.93$ & 654.38 & 141 & 70.97 & 0.000 \\
\hline Irinotecan & $110,392.37$ & 479.97 & 230 & 160.35 & $314,532.29$ & 933.33 & 337 & 326.02 & $58,111.84$ & 496.68 & 117 & 97.90 & 0.000 \\
\hline Irinotecan mono & 0.00 & 0.00 & 0 & - & 0.00 & 0.00 & 0 & - & 0.00 & 0.00 & 0 & - & - \\
\hline Oxaliplatin & $204,218.64$ & 903.62 & 226 & 224.06 & $124,504.41$ & 936.12 & 133 & 193.88 & $21,271.49$ & 686.18 & 31 & 8.51 & 0.164 \\
\hline Cetuximab & $2,700.13$ & $1,350.07$ & 2 & 372.07 & $291,095.08$ & $1,311.24$ & 222 & 276.62 & $25,480.90$ & $1,341.10$ & 19 & 384.24 & 0.844 \\
\hline Cetuximab mono & 0.00 & 0.00 & 0 & - & $1,342.33$ & $1,342.33$ & 1 & - & 0.00 & 0.00 & 0 & - & - \\
\hline Bevacizumab & $34,559.56$ & $1,681.99$ & 80 & 357.94 & $271,544.31$ & $1,859.89$ & 146 & 349.56 & $30,906.09$ & $1,717.01$ & 18 & 166.89 & 0.000 \\
\hline Bevacizumab mono & 0.00 & 0.00 & 0 & - & $12,492.65$ & $2,498.53$ & 5 & 0.00 & 0.00 & 0.00 & 0 & - & - \\
\hline Panitumumab & 0.00 & 0.00 & 0 & - & $33,874.56$ & $2,822.88$ & 12 & 0.00 & 0.00 & 0.00 & 0 & - & - \\
\hline Carboplatin & 0.00 & 0.00 & 0 & - & 0.00 & 0.00 & 0 & - & $1,989.91$ & 284.27 & 7 & 3.21 & - \\
\hline Docetaxel & 0.00 & 0.00 & 0 & - & 0.00 & 0.00 & 0 & - & $4,484.94$ & 747.49 & 6 & 0.00 & - \\
\hline Total drug costs & $867,549.05$ & 677.77 & 1,280 & 339.88 & $1,372,579.37$ & 829.85 & 1,654 & 560.79 & $234,512.10$ & 691.78 & 339 & 334.03 & 0.000 \\
\hline
\end{tabular}

Values represent euros. ${ }^{1}$ Variance analysis, centers A and B; Student's t test/Welch's t test.

Table 6. Drug costs for palliative care at the 3 centers with double-figure recruitment numbers during the second year of treatment

\begin{tabular}{|c|c|c|c|c|c|c|c|c|c|c|c|c|c|}
\hline \multirow[t]{2}{*}{ Drug } & \multicolumn{4}{|c|}{ Center A (19 patients) } & \multicolumn{4}{|c|}{ Center B (22 patients) } & \multicolumn{4}{|c|}{ Center C (4 patients) } & \multirow{2}{*}{$\begin{array}{l}\mathrm{p} \\
\text { value }\end{array}$} \\
\hline & total & VAT & $\mathrm{n}$ & SD & total, EUR & VAT, EUR & $\mathrm{n}$ & SD & total, EUR & VAT, EUR & $\mathrm{n}$ & SD & \\
\hline 5-FU + folinic acid & $180,147.09$ & 549.23 & 328 & 137.81 & $113,711.33$ & 370.40 & 307 & 187.97 & $43,664.46$ & 598.14 & 73 & 73.21 & 0.000 \\
\hline Irinotecan & $109,265.27$ & 449.65 & 243 & 113.55 & $180,811.31$ & 966.91 & 187 & 211.45 & $25,094.98$ & 464.72 & 54 & 62.10 & 0.000 \\
\hline Irinotecan mono & 0.00 & 0.00 & 0 & - & $2,471.48$ & $1,235.74$ & 2 & 180.72 & 0.00 & 0.00 & 0 & - & - \\
\hline Oxaliplatin & $40,285.61$ & 789.91 & 51 & 229.83 & $11,956.26$ & 996.36 & 12 & 139.51 & $8,920.39$ & 892.04 & 10 & 120.58 & 0.004 \\
\hline Cetuximab & $89,691.80$ & $1,379.87$ & 65 & 319.20 & $183,394.21$ & $1,273.57$ & 144 & 359.17 & 0.00 & 0.00 & 0 & - & 0.042 \\
\hline Cetuximab mono & 0.00 & 0.00 & 0 & - & 0.00 & 0.00 & 0 & - & 0.00 & 0.00 & 0 & - & - \\
\hline Bevacizumab & $119,736.14$ & $1,478.22$ & 81 & 518.72 & $180,380.91$ & $1,939.58$ & 93 & 533.45 & $27,137.28$ & $1,596.31$ & 17 & 34.13 & 0.000 \\
\hline Bevacizumab mono & 0.00 & 0.00 & 0 & - & $14,991.18$ & $2,498.53$ & 6 & 0.00 & 0.00 & 0.00 & 0 & - & - \\
\hline Panitumumab & 0.00 & 0.00 & 0 & - & $17,864.64$ & $2,977.44$ & 6 & 224.61 & 0.00 & 0.00 & 0 & - & - \\
\hline Total drug costs & $539,125.91$ & 701.99 & 768 & 430.60 & $705,581.32$ & 932.08 & 757 & 643.02 & $104,817.11$ & 680.63 & 154 & 347.30 & 0.000 \\
\hline
\end{tabular}

Values represent euros. VAT = Value added tax. ${ }^{1}$ Variance analysis, centers A and B; Student's t test/Welch's $t$ test.

In the context of the IVOPAK project, the computed tomography (CT) images (spiral CT images of the abdomen and chest) obtained prior to the onset of the palliative first-line treatment were generally used to assess the resectability status (table 1). Overall, the CT images of more than $50 \%$ of the IVOPAK patients were presented at an interdisciplinary tumor board prior to initiation of the palliative first-line treatment, although not all of the study centers drew support from the interdisciplinary tumor boards.

In terms of patient characteristics, the IVOPAK collective demonstrates different patient characteristics than those of the patient collectives of other major palliative phase III studies [17-21]. For example, the median age of the IVOPAK patient group was 70 years (table 2), whereas in the intergroup study comparing irinotecan to oxaliplatin-containing regimens (N9741), it was 61 years [18]; in the BICC-C study (Randomized, Controlled Trial of Irinotecan plus Infusional, Bolus or Oral Fluoropyrimidine), it was 61 years [17]; in the OPTIMOX1 study (Randomized Study of FOLFOX4 or FOLFOX7 with Oxaloplatin in a Stop-And-Go Fashion in Advanced CRC), it was 61 years [19], and in the GERCOR study (Groupe Coopérateur Multi- 


\section{Oncology}

\begin{tabular}{l|l}
\hline Oncology 2015;88:103-121 \\
\hline DOI: 10.1159/000368246 & $\begin{array}{l}\text { @ 2014 S. Karger AG, Basel } \\
\text { www.karger.com/ocl }\end{array}$ \\
\hline
\end{tabular}

Wein et al.: Palliative Treatment of Colorectal Cancer with Secondary Metastasis Resection in Germany

disciplinaire en Oncologie) on sequential treatment, the median age was 61 years [20]. Furthermore, in the CRYSTAL study (Cetuximab Combined with Irinotecan in First-Line Therapy for Metastatic CRC), the median age was 61 years [7], and in the FIRE-3 study (Randomized Comparison of FOLFIRI plus Cetuximab vs. FOLFIRI plus Bevacizumab FirstLine Treatment of KRAS Wild-Type Metastatic CRC: German AIO Study KRK0306), it was 64 years [6]. Although the age parameter does not constitute a prognostic factor [22], it is obvious that the IVOPAK project did not conduct selective procedures prior to patient enrollment and treatment initiation. The relatively advanced age of the IVOPAK patients most probably reflects demographic changes in palliative treatment in Germany. The performance status (according to the current ECOG index) has been shown in multivariate analysis to be an important prognostic factor for the palliative first-line treatment of CRC [22]. The comparatively high percentage of patients $(13 \%)$ in the IVOPAK study with the unfavorable ECOG grade 2 prognostic factor also illustrates that all patients meeting the inclusion criteria were enrolled in the IVOPAK study. The frequency of patients with ECOG grade 2 in other phase III studies is often in the single-figure range $[4,6,7,23,24]$.

In terms of other patient characteristics such as gender, primary tumor location and the frequency of synchronous or metachronous metastases, the IVOPAK patients did not significantly differ from the patient collectives of other phase III studies [17-21].

The main high-grade toxicities (NCI-CTC grade 3/4) in the palliative first-line treatment of 103 IVOPAK patients were related to gastrointestinal toxicity, i.e. diarrhea $(13 \%$; $95 \% \mathrm{CI}$ : 6.2-19.0) and nausea/vomiting (6\%; 95\% CI: 0.7-9.0), as shown in table 3. High-grade hematological toxicity was only observed in isolated cases. All patients of the IVOPAK collective were treated with irinotecan-/oxaliplatin-based combined regimens or 5-FU monotherapy and the observed NCI-CTC toxicity might be considered somewhat more favorable than the higher-grade toxicities arising in the abovementioned first-line studies.

In the N9741 phase III study, 267 patients were treated first-line with FOLFOX4. Highgrade NCI-CTC toxicities (grade 3/4) in the form of diarrhea (14\%) and severe nausea/ vomiting (3\%) were observed [18]. In the OPTIMOX1 phase III study, 311 patients received FOLFOX4 as first-line treatment up to disease progression [19]. In this case, high-grade NCI-CTC toxicities (grade 3/4) were observed in 11\% (diarrhea) and 5\% (nausea/vomiting) of patients [19]. The BICC-C phase III study compared various irinotecan-based combined chemotherapy regimens [17]. In terms of high-grade toxicities, diarrhea occurred in $13.9 \%$ of the FOLFIRI-treated patients $(n=137)$ and nausea/vomiting in $17.6 \%$ [17]. The CRYSTAL phase III study applied FOLFIRI in 1 treatment arm comprising 599 patients. In this study, high-grade toxicity occurred in the form of diarrhea in $14.9 \%$ and vomiting in $4.5 \%$ of patients [7].

Colucchi et al. [21] recruited 360 patients for their phase III study comparing the efficacy of FOLFIRI versus FOLFOX4 in first-line treatment. In the FOLFIRI treatment arm, high-grade NCI-CTC grade $3 / 4$ toxicities were diarrhea in $10 \%$ of patients and nausea/vomiting in $4 \%$, whereas in the FOLFOX4 arm, severe NCI-CTC toxicities were seen in 5\% (diarrhea) and 3\% (nausea/vomiting) of patients. High-grade leukocytopenia was observed at a frequency of 3\% for both schedules [21]. The EORTC (European Organization for Treatment of Cancer) 40986 phase III study conducted by Köhne et al. [25] comprised 430 patients who were enrolled for palliative first-line treatment and used in one arm the AIO plus irinotecan regimen [AIO regimen: 2 -hour infusion of folinic acid $\left(500 \mathrm{mg} / \mathrm{m}^{2}\right)$ followed by $5-\mathrm{FU} / 2,000 \mathrm{mg} / \mathrm{m}^{2}$ i.v. as a 24-hour infusion, on days 1, 8, 15, 22, 29, 36 qd 57 with weekly IRI $\left(80 \mathrm{mg} / \mathrm{m}^{2}\right)$ as 0.5 -hour infusion]. In this study arm, severe NCT-CTC toxicities (grade $3 / 4$ ) were diarrhea in $24 \%$ and nausea/vomiting in $17 \%$ of the patients [25].

The favorable overall toxicity observed in the IVOPAK patient collective might be explained by the mixed chemotherapeutic approach. On the other hand, it may be attrib- 


\section{Oncology}

\begin{tabular}{l|l}
\hline Oncology 2015;88:103-121 \\
\hline DOI: 10.1159/000368246 & $\begin{array}{l}\text { @ 2014 S. Karger AG, Basel } \\
\text { www.karger.com/ocl }\end{array}$ \\
\hline
\end{tabular}

Wein et al.: Palliative Treatment of Colorectal Cancer with Secondary Metastasis Resection in Germany

utable to the relatively short treatment duration of first-line therapy in some centers, e.g. PFS of 4 months at center $C$, and furthermore, by the comparatively high rate of secondary metastasis resection, which frequently entails a short period of first-line chemotherapy treatment.

With a median OS of 25 months, the OS rates achieved by the IVOPAK patients $(n=103)$ can be considered favorable, particularly since only 33 of the IVOPAK patients (32\%) had received biological agents such as bevacizumab or cetuximab in first-line treatment. The IVOPAK patients were treated mainly with either oxaliplatin- or irinotecan-based regimens via portacath. In the phase III trial conducted by Colucci et al. [21], the patients receiving firstline FOLFIRI achieved a median OS of 14 months; for the patients receiving FOLFOX4, median OS was 15 months. In the N9741 Intergroup phase III study, a median OS of 19.5 months was observed in the patient group treated with FOLFOX4 [18], a result similar to that of the OPTIMOX1 study with a median OS of 19.3 months among the patients of the FOLFOX4 arm [19]. In the EORTC 40986 phase III study, AIO plus irinotecan was applied to achieve a median OS of 20.1 months [25]. In the CRYSTAL phase III study, the median OS of the patients treated with first-line FOLFIRI $(n=599)$ amounted to 20 months [7]. The main reason for the high median OS of 25 months achieved in the IVOPAK study might be explained by the relatively high number of patients who had undergone secondary metastasis resection $(n=27)$, as this is known to be associated with a favorable OS (fig. 3).

The patients of the IVOPAK study $(n=103)$ achieved a PFS of just 7 months with the firstline treatment. However, as shown in figure 5, the PFS achieved by the centers A, B and C differed significantly $(\mathrm{p}<0.001)$ between center A (achieving a PFS of 10 months) and center $\mathrm{C}$ (achieving a PFS of 4 months). The IVOPAK patients may be considered to have been treated with a mixed chemotherapeutic approach, receiving different medication types and schedules ranging from 5-FU monotherapy to combined chemotherapy and combined chemotherapy plus biological agents. Therefore, the main reason for the relatively low median PFS may be the limited number of patients (only 32\%) who received biological agents during first-line treatment within the framework of the IVOPAK study. A similarly unfavorable PFS of 7 months was found in the phase III study conducted by Colucci et al. [21] investigating FOLFIRI versus FOLFOX4 as the first-line treatment. The OPTIMOX phase III study focused on the FOLFOX4 schedule achieved a median PFS of 9.0 months 19]; the Intergroup N9741 phase III study applying FOLFOX4 recorded a PFS of 8.7 months [18] and the GERCOR study by Tournigand et al. [20] applied FOLFOX6 to achieve a PFS of 8.1 months. The EORTC 40986 phase III study patient collective received the AIO regimen plus irinotecan as the first-line treatment and had a median PFS of 8.5 months [25], whereas the patient group treated with the AIO regimen alone achieved a median PFS of solely 6.4 months.

In the CRYSTAL first-line treatment study, the FOLFIRI group reached a median PFS of 8.4 months [7]. The median PFS of 7.0 months achieved in the IVOPAK study - characterized by its mixed chemotherapeutic approach - is comparable to the EORTC 40986 study [25]. The relatively high median PFS of 10.0 months in center A might be explained by the relatively high rate of secondary metastasis resection of $40 \%$ in the palliative patients, the influence of which on the PFS rate is represented in figure 5. The considerable differences in terms of PFS and OS between the abovementioned studies can also be explained by the numerous influencing prognostic factors that may affect both OS and PFS rates [28].

The ORR for the total IVOPAK collective amounted to 38\% and 1 patient (1\%) achieved radiological CR. In the phase III study of Colucci et al. [21], the ORR of the subgroup treated with the FOLFIRI regimen was 31\%, and this was 34\% for the subgroup that had received FOLFOX4. In the BICC-C study, an ORR of $47 \%$ was observed in patients treated with FOLFIRI [17]. In the OPTIMOX1 study, patients of the FOLFOX4 arm had an ORR of 58\% [19]. The GERCOR study achieved an ORR of 54\% in patients receiving FOLFOX6 as the first-line 


\section{Oncology}

\begin{tabular}{l|l}
\hline Oncology 2015;88:103-121 \\
\hline DOI: $10.1159 / 000368246$ & $\begin{array}{l}\text { @ 2014 S. Karger AG, Basel } \\
\text { www.karger.com/ocl }\end{array}$ \\
\hline
\end{tabular}

Wein et al.: Palliative Treatment of Colorectal Cancer with Secondary Metastasis

Resection in Germany

Table 7. First-line therapy for CRC within the IVOPAK I study: frequency of the application of specific first-line therapy regimens, activities at the interdisciplinary interface and their results

\begin{tabular}{|c|c|c|c|c|c|c|c|c|c|c|c|c|c|}
\hline & \multicolumn{3}{|c|}{ Total cohort } & \multicolumn{3}{|c|}{ Center A } & \multicolumn{3}{|c|}{ Center B } & \multicolumn{3}{|l|}{ Center C } & \multirow{2}{*}{$\begin{array}{l}\text { Fisher's } \\
\text { exact } \\
\text { test } \\
\text { p value }\end{array}$} \\
\hline & $\begin{array}{l}\text { patients, } \\
\mathrm{n}\end{array}$ & regimen & $\mathrm{n}$ & $\begin{array}{l}\text { patients } \\
\mathrm{n}\end{array}$ & regimen & $\mathrm{n}$ & $\begin{array}{l}\text { patients } \\
\mathrm{n}\end{array}$ & regimen & $\mathrm{n}$ & $\begin{array}{l}\text { patients, } \\
\mathrm{n}\end{array}$ & regimen & $\mathrm{n}$ & \\
\hline $\begin{array}{l}\text { 5-FU } \\
\text { monotherapy }\end{array}$ & $\begin{array}{l}6 / 103 \\
(6 \%)\end{array}$ & $\begin{array}{l}\text { AIO } \\
\text { capecitabine } \\
\text { capecitabine+bev. }\end{array}$ & $\begin{array}{l}4 \\
1 \\
1\end{array}$ & $\begin{array}{l}4 / 37 \\
(11 \%)\end{array}$ & AIO & 4 & $\begin{array}{l}0 / 35 \\
(0 \%)\end{array}$ & - & & $\begin{array}{l}0 / 10 \\
(0 \%)\end{array}$ & - & & 0.139 \\
\hline $\begin{array}{l}\text { Oxaliplatin- } \\
\text { based } \\
\text { combination } \\
\text { chemotherapy }\end{array}$ & $\begin{array}{l}33 / 103 \\
(32 \%)\end{array}$ & $\begin{array}{l}\text { FOLFOX4 } \\
\text { AIO+oxaliplatin } \\
\text { FOLFOX6 } \\
\text { Xelox } \\
\text { FUFOX1 }\end{array}$ & $\begin{array}{r}11 \\
14 \\
5 \\
2 \\
1\end{array}$ & $\begin{array}{l}19 / 37 \\
(51 \%)\end{array}$ & $\begin{array}{l}\text { AIO+oxaliplatin } \\
\text { FOLFOX6 }\end{array}$ & $\begin{array}{r}14 \\
5\end{array}$ & $\begin{array}{l}10 / 35 \\
(29 \%)\end{array}$ & FOLFOX4 & 10 & $\begin{array}{l}2 / 10 \\
(20 \%)\end{array}$ & $\begin{array}{l}\text { FUFOX } \\
\text { FOLFOX4 }\end{array}$ & $\begin{array}{l}1 \\
1\end{array}$ & 0.061 \\
\hline $\begin{array}{l}\text { Irinotecan- } \\
\text { based } \\
\text { combination } \\
\text { chemotherapy }\end{array}$ & $\begin{array}{l}31 / 103 \\
(30 \%)\end{array}$ & $\begin{array}{l}\text { FOLFIRI } \\
\text { AIO+iri. } \\
\text { Xeliri } \\
\text { IFL }\end{array}$ & $\begin{array}{r}14 \\
17 \\
- \\
-\end{array}$ & $\begin{array}{l}8 / 37 \\
(22 \%)\end{array}$ & $\begin{array}{l}\text { FOLFIRI } \\
\text { AIO+iri. }\end{array}$ & $\begin{array}{l}3 \\
5\end{array}$ & $\begin{array}{l}4 / 35 \\
(11 \%)\end{array}$ & FOLFIRI & 4 & $\begin{array}{l}7 / 10 \\
(70 \%)\end{array}$ & AIO+iri. & 7 & 0.001 \\
\hline $\begin{array}{l}\text { Cetuximab + } \\
\text { chemotherapy }\end{array}$ & $\begin{array}{l}9 / 103 \\
(9 \%)\end{array}$ & $\begin{array}{l}\text { FOLFIRI+cetuxi. } \\
\text { FOLFOX4+cetuxi. } \\
\text { AIO+iri.+cetuxi. }\end{array}$ & $\begin{array}{l}7 \\
1 \\
1\end{array}$ & - & - & & $\begin{array}{l}8 / 35 \\
(23 \%)\end{array}$ & $\begin{array}{l}\text { FOLFIRI+cetuxi. } \\
\text { FOLFOX4+cetuxi. }\end{array}$ & $\begin{array}{l}7 \\
1\end{array}$ & $\begin{array}{l}1 / 10 \\
(10 \%)\end{array}$ & $\begin{array}{l}\text { AIO+iri.+ } \\
\text { cetuxi. }\end{array}$ & 1 & 0.659 \\
\hline $\begin{array}{l}\text { Bevacizumab + } \\
\text { chemotherapy }\end{array}$ & $\begin{array}{l}24 / 103 \\
(23 \%)\end{array}$ & $\begin{array}{l}\text { FOLFIRI+bev. } \\
\text { AIO+iri.+bev. } \\
\text { FOLFOX4+bev. } \\
\text { AIO+oxaliplatin+bev. }\end{array}$ & $\begin{array}{r}16 \\
4 \\
2 \\
2\end{array}$ & $\begin{array}{l}6 / 37 \\
(16 \%)\end{array}$ & $\begin{array}{l}\text { AIO+iri.+bev. } \\
\text { AIO+oxaliplatin+bev. }\end{array}$ & $\begin{array}{l}4 \\
2\end{array}$ & $\begin{array}{l}13 / 35 \\
(37 \%)\end{array}$ & $\begin{array}{l}\text { FOLFIRI+bev. } \\
\text { FOLFOX4+bev. }\end{array}$ & $\begin{array}{r}12 \\
1\end{array}$ & $\begin{array}{l}0 / 10 \\
(0 \%)\end{array}$ & - & & 0.020 \\
\hline $\begin{array}{l}\text { Secondary } \\
\text { metastasis } \\
\text { resection }\end{array}$ & $\begin{array}{l}27 / 103 \\
(26 \%)\end{array}$ & $\begin{array}{l}\text { FOLFIRI } \\
\text { FOLFIRI+cetuxi. } \\
\text { FOLFIRI+bev. } \\
\text { AIO+iri.+cetuxi. } \\
\text { AIO+oxaliplatin } \\
\text { FOLFOX6 } \\
\text { FOLFOX4 } \\
\text { AIO+oxaliplatin+bev. } \\
\text { AIO+iri.+bev. } \\
\text { AIO+iri. }\end{array}$ & $\begin{array}{l}1 \\
2 \\
6 \\
1 \\
5 \\
2 \\
3 \\
2 \\
3 \\
2\end{array}$ & $\begin{array}{l}15 / 37 \\
(40 \%)\end{array}$ & $\begin{array}{l}\text { AIO+oxaliplatin } \\
\text { FOLFOX6 } \\
\text { AIO+oxaliplatin+bev. } \\
\text { FOLFIRI } \\
\text { AIO+iri. } \\
\text { AIO+iri.+bev. }\end{array}$ & $\begin{array}{l}5 \\
2 \\
2 \\
1 \\
2 \\
3\end{array}$ & $\begin{array}{l}9 / 35 \\
(26 \%)\end{array}$ & $\begin{array}{l}\text { FOLFOX4 } \\
\text { FOLFIRI+bev. } \\
\text { FOLFIRI+cetuxi. }\end{array}$ & $\begin{array}{l}3 \\
4 \\
2\end{array}$ & $\begin{array}{l}1 / 10 \\
(10 \%)\end{array}$ & FOLFOX4 & 1 & 0.139 \\
\hline R0 resection & $\begin{array}{l}22 / 27 \\
(81 \%)\end{array}$ & & & $\begin{array}{l}14 / 15 \\
(93 \%)\end{array}$ & - & & $\begin{array}{l}6 / 9 \\
(66 \%)\end{array}$ & & & $\begin{array}{l}0 / 1 \\
(0 \%)\end{array}$ & & & 0.054 \\
\hline $\begin{array}{l}\text { NED of R0- } \\
\text { resected patients }\end{array}$ & $\begin{array}{l}10 / 22 \\
(45 \%)\end{array}$ & - & & $\begin{array}{l}8 / 14 \\
(57 \%)\end{array}$ & - & & $\begin{array}{l}1 / 6 \\
(17 \%)\end{array}$ & - & & $\begin{array}{l}\mathrm{n}=0 \\
(0 \%)\end{array}$ & - & & 0.157 \\
\hline
\end{tabular}

iri. = Irinotecan; cetuxi. = cetuximab; bev. = bevacizumab; IFL = iri., 5-FU bolus i.v., folinic acid bolus i.v.; AIO = 5-FU $/ 2,600$ mg $/ \mathrm{m}^{2}$ i.v. simultaneously with sodium folinic acid $\left(500 \mathrm{mg} / \mathrm{m}^{2}\right)$ as a 24-hour infusion on days $1,8,15,22,29,36 \mathrm{qd} 57$.

regimen [20], whereas the FOLFIRI-treated patients had an ORR of 56\% [20]. In the CRYSTAL study, the ORR of patients with wild-type K-RAS tumors treated with first-line FOLFIRI was $39 \%$ [7].

Secondary metastasis resection subsequent to downsizing of the metastases by first-line chemotherapy may make a considerable contribution to achieving the following primary treatment objectives.

Multimodal treatment procedures could increase CR rates (i.e. radiological PR achieved by chemotherapy plus secondary metastasis resection). To date, the rate of radiological CR that can be obtained by chemotherapy (e.g. FOLFIRI) plus biological agents (e.g. cetuximab for proven wild-type K-RAS tumors) amounts to approximately $3 \%$ [7]. Within the IVOPAK study, the rate of radiological CR could be increased from $1 \%$, obtained by means of chemotherapy treatment alone, to $6 \%$ by applying multimodal treatment procedures (i.e. radiological PR plus secondary metastasis resection). Patients with CR during first-line treatment achieved the most favorable median survival rates in the N9741 phase III study [29]. The application of the aggressive FOLFOXIRI regimen also resulted in elevated radiological CR rates (5\%), which were obtained by means of chemotherapy treatment alone [23]. Due to its 


\section{Oncology}

\begin{tabular}{l|l}
\hline Oncology 2015;88:103-121 \\
\hline DOI: 10.1159/000368246 & $\begin{array}{l}\text { @ 2014 S. Karger AG, Basel } \\
\text { www.karger.com/ocl }\end{array}$ \\
\hline
\end{tabular}

Wein et al.: Palliative Treatment of Colorectal Cancer with Secondary Metastasis Resection in Germany
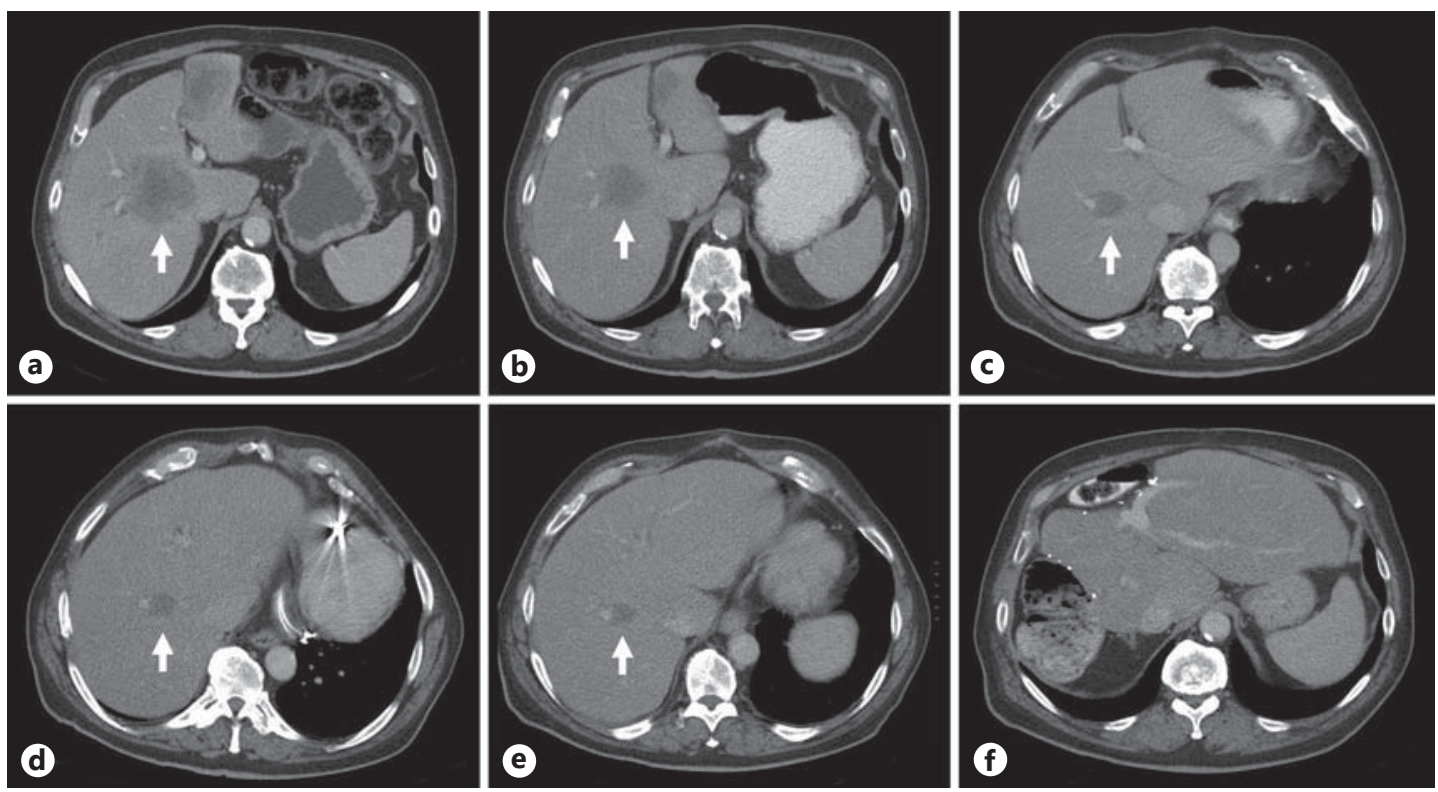

Fig. 7. Regular follow-up evaluations with presentation of CT images to the interdisciplinary tumor board. Evaluations were conducted at 8-week intervals during first-line treatment (CCS). a Prechemotherapy (June 27, 2007). b After the first cycle (September 11, 2007; 2 months of therapy). c After the second cycle; PR (November 13, 2007; 4 months of therapy).d After the third cycle; confirmed PR (January 15, 2008; 6 months of therapy). e After the fourth cycle (March 25, 2008; 8 months of therapy). f Postoperative, last follow-up (11/2011); time after hemihepatectomy (right) + segment resection III (R0); pathohistological CR.

wide range of higher-grade toxicities and side effects, the FOLFOXIRI regimen is neither commonly applied in palliative first-line CRC treatment in Germany, nor does it play a role in the first-line treatment schedules of the IVOPAK centers (table 7).

By obtaining an increase in the number of patients with curative options subsequent to R0 resection of secondary metastases, a conversion from the palliative to a curative situation can be achieved by applying multimodal treatment procedures [30]. In 10 out of 103 (10\%) palliative patients, the IVOPAK project achieved a fairly long-term conversion from a palliative to a curative situation after performing secondary metastasis resection subsequent to chemotherapy (table 7). However, the IVOPAK results point to the fact that not all of the participating centers were seeking support in the form of interdisciplinary cooperation. An optimized interdisciplinary cooperation should thus be considered as a desirable future objective, particularly in view of improved patient care. Aside from the positive longterm results in the form of NED, the patient cohort treated with multimodal procedures $(\mathrm{n}=27)$ achieved a median OS of 49 months (fig. 3). This emphasizes the crucial importance of interdisciplinary cooperation in terms of improved outcome - even in palliative CRC situations.

In the IVOPAK project, resections of secondary metastases were performed subsequent to downsizing of distant metastases during first-line treatment only. This might be explained by the fact that established second-line schedules have yielded relatively low response rates [20, $24,26]$. Second-line treatment schedules with higher response rates, e.g. FOLFIRI plus aflibercept (response rate: $\sim 20 \%$ ), could give rise to a change or secondary metastasis resection during second-line chemotherapy [31]. Study results on this topic remain to be seen. The IVOPAK project confirms that secondary metastasis resections were most frequently applied to patients 


\section{Oncology}

\begin{tabular}{l|l}
\hline Oncology 2015;88:103-121 \\
\hline DOI: $10.1159 / 000368246$ & $\begin{array}{l}\text { @ 2014 S. Karger AG, Basel } \\
\text { www.karger.com/ocl }\end{array}$ \\
\hline
\end{tabular}

Wein et al.: Palliative Treatment of Colorectal Cancer with Secondary Metastasis Resection in Germany

with liver-only metastases [32]. However, it should be stated that patients with other metastatic locations - e.g. lung-only or peritoneal carcinomatosis metastases, or patients with combined distant metastases - should not, in principle, be excluded from secondary metastasis resection. In cases where surgery is possible, the CT scans of the affected patients should be presented to an interdisciplinary tumor board. Additionally, promising results could be achieved by regularly presenting the CT scans to an interdisciplinary tumor board (Continuous Check Strategy, CCS; fig. 7) during the course of treatment, e.g. every 2 months. Such a strategy would enable the most favorable time point at which to perform a possible secondary metastasis resection to be identified. The participating IVOPAK centers were not restricted by any rules or regulations in terms of treatment decisions. In center A, a CCS (fig. 6) was regularly carried out due to positive experiences gained in previous studies [11, 27].

This may explain the relatively high rate of secondary metastasis resections of $40 \%$ in patients with primarily nonresectable distant metastases. Moreover, both the favorable median OS of 27 months and the favorable PFS of 10 months in center A might be explained by considering the high rate of secondary metastasis resections (40\%) and the influence of this on OS and PFS (fig. 3). Since only $16 \%$ of patients in center A received biological agents in first-line treatment, the influence of biological agents on OS and PFS in center A is likely to be limited (table 7), and this area of treatment requires optimization.

The favorable outcome in terms of median OS of the IVOPAK patient group treated in a multimodal context clearly surpasses the median OS of the patient group treated with chemotherapy alone (fig. 3). The improved outcome of the multimodal group is comparable with the outcome results of other studies. For example, in a retrospective analysis of patients with isolated peritoneal carcinomatosis of CRC, Elias et al. [33] demonstrated that 48 patients who had received palliative chemotherapy alone had a median survival of 23.9 months, whereas 48 patients who had been treated in a multimodal context (i.e. peritonectomy plus hyperthermic intraperitoneal chemotherapy with oxaliplatin) achieved a median survival of 62.7 months. After a median follow-up of 95.7 months, the 5-year survival rate was 13 versus $51 \%$, thus demonstrating a clear advantage of the multimodal treatment over chemotherapy alone. Out of 119 patients suffering from nonresectable liver metastases of CRC who had been enrolled into a randomized EORTC phase II study, 59 patients received systemic combined chemotherapy based on 5-FU/folinic acid and oxaliplatin plus/minus bevacizumab up to tumor progression and 60 patients received systemic chemotherapy with radiofrequency ablation plus/minus secondary metastasis resection [34]. Median OS was 40.5 months for the patient group receiving systemic treatment and 45.3 months for the patient group treated according to multimodal procedures. The 3-year PFS rates were 27.6 and $10.6 \%$ for the multimodal and systemic treatments, respectively. Kopetz et al. [35] retrospectively investigated the outcome of 2,470 patients with metastatic CRC and assessed a continuous improvement in terms of median survival from 2000 to 2006. During the observational period between 2004 and 2006, median survival was 29.3 months. This outcome is comparable to the OS of the total collective observed in the IVOPAK study. In the authors' opinion, the increased application of new chemotherapeutical agents and incremental increases in the rate of secondary liver metastasis resections gave rise to this positive result. The outcome of the IVOPAK study demonstrates that remarkable improvements are achievable in palliative situations, on the condition that multimodal treatment procedures, close interdisciplinary cooperation, and appropriate secondary metastasis resection methods are adhered to. By observing the aforementioned considerations, the multimodal patient group of the IVOPAK study achieved a median OS of 49 months (fig. 3) and a median PFS of 18 months (fig. 6).

With a median survival of 47 months in the multimodal patient group ( $\mathrm{n}=34$ ), the outcome in the GERCOR study conducted by Tournigand et al. [20] presents similar results. 


\section{Oncology}

\begin{tabular}{l|l}
\hline Oncology 2015;88:103-121 \\
\hline DOI: 10.1159/000368246 & $\begin{array}{l}\text { @ 2014 S. Karger AG, Basel } \\
\text { www.karger.com/ocl }\end{array}$ \\
\hline
\end{tabular}

Wein et al.: Palliative Treatment of Colorectal Cancer with Secondary Metastasis Resection in Germany

More than ever, it is of vital importance to implement the European Society for Medical Oncology (ESMO) Guidelines, which recommend that 'The management of CRC must be a multimodal approach by an experienced multidisciplinary expert team' [3].

The cost of care for palliative treatment of CRC in all IVOPAK patients $(n=103)$ during the first and second years has been calculated and published previously [9]. The major cost drivers in palliative treatment were drug costs (cytostatic drugs plus biological agents and biomodulators) in the IVOPAK collective, which amounted to 4,298,327.86 [9]. This corresponds to $70 \%$ of the total accumulated costs of palliative care [9]. Comparative analyses in terms of cost-of-care evaluations for palliative CRC treatment in Germany still remain to be accomplished. A systematic international review published by Kriza et al. [36] demonstrated that the initial and terminal phases of CRC care are the most expensive, with continuing treatment being the most costly phase. A cost-of-care evaluation in French palliative CRC patients demonstrated an increase in costs from 17,596 to 35,099 that was related to the deteriorating stage of disease, i.e. from Union for International Cancer Control (UICC) stage I to UICC stage IV [37]. In this cost analysis, 'medical purchases' ranked second in terms of expenditures. This is explained by the fact that the proportion of patients in UICC stage IV who required mainly systemic treatment was relatively low. In addition, this French analysis evaluated costs during the first year after diagnosis only. A review on costs of care in CRC ascertained a trend for rising costs, which is related to the increasing application of biological agents in CRC treatment [36]. Owing to the similar number of enrolled patients in centers $A(n=37)$ and $B(n=35)$, the figures from these 2 centers would appear to be simply comparable. In the first year of treatment, drug costs (cytostatic agents, biological agents and biomodulators) were the main cost drivers (table 4). Significant differences were observed in terms of drug costs between centers A and B during the first and second years of treatment (tables 5,6 ). The treatment preferences and peculiarities of centers A and B were also reflected by differences in drug costs and applied agents (tables 5,6$)$.

The costs reflect the preferences of the centers for particular agents and schedules. For example, $63 \%$ of center B patients received biological agents during first-line treatment. According to previously published studies, biological agents were mostly combined with FOLFIRI [6] and these combinations (i.e. FOLFIRI plus biological agents) frequently lead to long treatment durations (i.e. a high number of applications). Therefore, total costs for irinotecan and biologicals were significantly higher in center B. In comparison, center A produced significantly higher costs for 5 -FU, folinic acid and oxaliplatin than center B. Center A often preferred an oxaliplatin-based combined chemotherapy as the first-line treatment and mainly applied weekly infusion regimens in accordance with the AIO schedule (table 7). The AIO regimen generally comprises relatively high doses of 5-FU and folinic acid as compared to the biweekly schedules of FOLFIRI or FOLFOX4, for example. Apart from the preferences for specific schedules, the high rate of secondary metastasis resections in center A (table 7), which were mostly performed during first-line therapy (i.e. during the first year of treatment), represents a major factor contributing to the significant differences in costs between centers $\mathrm{A}$ and $\mathrm{B}$.

In center $\mathrm{A}$, secondary metastasis resections were performed in 15 out of 37 patients (40\%) and resulted in discontinuation of the formerly applied medication. Of the 14 R0-resected patients, 8 (57\%) remained NED and required no more drugs. This was associated with saving drug costs and thus limiting the main cost driver. The patients who maintained an NED status - 8 out of the 15 secondarily resected patients (53\%) in center A - also contributed to cost limitations during the second year of palliative treatment. This is a possible further reason for the observed differences in costs (table 5). 


\section{Oncology}

\begin{tabular}{l|l}
\hline Oncology 2015;88:103-121 \\
\hline DOI: 10.1159/000368246 & $\begin{array}{l}\text { @ 2014 S. Karger AG, Basel } \\
\text { www.karger.com/ocl }\end{array}$ \\
\hline
\end{tabular}

Wein et al.: Palliative Treatment of Colorectal Cancer with Secondary Metastasis Resection in Germany

\section{Conclusion}

Palliative treatment of metastatic CRC in the IVOPAK study was mostly performed in accordance with S3 treatment guidelines [2]. However, the clinical treatment reality in Northern Bavaria clearly requires optimization, which would potentially be achievable by the following:

- An increased use of approved and validated biological agents in first-line treatment. In the IVOPAK study, only $32 \%$ of patients received biological agents during first-line treatment.

- Region-wide accessibility of all oncological centers to an interdisciplinary tumor board with experience in metastasis surgery could optimize the rate of secondary metastasis resections and thus patient outcome.

- An improved implementation of sequential treatment, which has been made even more complex by the approval of new agents [31, 38].

- IVOPAK study illustrates that vital prognostic improvements in palliative treatment are obtained by close interdisciplinary cooperation.

- The patients of the center with the closest and most intensive interdisciplinary cooperation in terms of secondary metastasis resection had the most favorable outcome and their treatment was also associated with the lowest costs. In general, considerable differences - both in terms of outcome and quality of care - have been demonstrated between the centers with double-figure enrolment numbers, and these issues are to be improved in a future project.

\section{Acknowledgements}

The authors are indebted to Mrs. Gudrun Männlein, Department of Internal Medicine 1, for her study assistance, Mrs. Barbara Harich and Mrs. Monika Lindenberg for their study support, IMEREM/RPS Clinical Research, Nuremberg, Germany, for monitoring, and Dr. W. Brückl and Dr. F. Boxberger for their support in establishing the study protocol.

The study was supported by grants from AOK Bayern; Fresenius Kabi Deutschland GmbH, Bad Homburg; Medac, Wedel; Merck Serono GmbH, Darmstadt; Pfizer Pharma GmbH, Berlin, and Roche Pharma AG, Grenzach-Whylen.

\section{Disclosure Statement}

All authors have disclosed any possible conflicts of interest.

\section{References}

1 Ferlay J, Shin HR, Bray F, Forman D, Mathers C, Parkin DM: Estimates of worldwide burden of cancer in 2008: GLOBOCAN 2008. Int J Cancer 2010;15:2893-2917.

2 Schmiegel W, Pox C, Reinacher-Schick A, Adler G, Fleig W, Fölsch UR, Frühmorgen P, Graeven U, Hohenberger W, Holstege A, Junginger T, Kopp I, Kühlbacher T, Porschen R, Propping P, Riemann JF, Rödel C, Sauer R, Sauerbruch T, Schmitt W, Schmoll HJ, Zeitz M, Selbmann HK: S3-Leitlinie 'Kolorektales Karzinom' - Ergebnisse evidenzbasierter Konsensuskonferenzen am 6./7. Februar 2004 und am 8./9. Juni 2007 (für die Themenkomplexe IV, V und VII). Z Gastroenterol 2008;46:1-73.

-3 Schmoll HJ, Van Cutsem E, Stein A, Valentini V, Glimelius B, Haustermans K, Nordlinger B, van de Velde CJ, Balmana J, Regula J, Nagtegaal ID, Beets-Tan RG, Arnold D, Ciardiello F, Hoff P, Kerr D, Köhne CH, Labianca R, Price T, Scheithauer W, Sobrero A, Tabernero J, Aderka D, Barroso S, Bodoky G, Douillard JY, El Ghazaly H, Gallardo J, Garin A, Glynne-Jones R, Jordan K, Meshcheryakov A, Papamichail D, Pfeiffer P, Souglakos I, Turhal S, Cervantes A: ESMO Consensus Guidelines for management of patients with colon and rectal cancer: a personalized approach to clinical decision making. Ann Oncol 2012;23:2479-2516. 


\section{Oncology}

\begin{tabular}{l|l}
\hline Oncology 2015;88:103-121 \\
\hline DOI: 10.1159/000368246 & $\begin{array}{l}\text { @ 2014 S. Karger AG, Basel } \\
\text { www.karger.com/ocl }\end{array}$ \\
\hline
\end{tabular}

Wein et al.: Palliative Treatment of Colorectal Cancer with Secondary Metastasis Resection in Germany

-4 Hurwitz H, Fehrenbacher L, Novotny W, Cartwright T, Hainsworth J, Heim W, Berlin J, Baron A, Griffing S, Holmgren E, Ferrara N, Fyfe G, Rogers B, Ross R, Kabbinavar F: Bevacizumab plus irinotecan, fluorouracil, and leucovorin for metastatic colorectal cancer. N Engl J Med 2004;350:2335-2342.

5 Fuchs CS, Marshall J, Barrueco J: Randomized, controlled trial of irinotecan plus infusional, bolus, or oral fluoropyrimidines in first-line treatment of metastatic colorectal cancer: updated results from the BICC-C study. J Clin Oncol 2008;26:689-690.

6 Heinemann V, Fischer von Weikersthal L, Decker T, Kiani A, Vehling-Kaiser U, Al-Batran A-E, Heintges T, Lerchenmueller J, Kahl C, Seipelt G, Kullmann F, Stauch M, Scheithauer W, Hielscher J, Scholz M, Mueller S, Schaefer B, Modest DP, Jung A, Stintzing S: Randomized comparison of FOLFIRI plus cetuximab versus FOLFIRI plus bevacizumab as first-line treatment of KRAS wild-type metastatic colorectal cancer: German AIO study KRK-0306 (FIRE-3). J Clin Oncol 2013;31(suppl abstr LBA3506).

-7 Van Cutsem E, Köhne CH, Láng I, Folprecht G, Nowacki MP, Cascinu S, Shchepotin I, Maurel J, Cunningham D, Tejpar S, Schlichting M, Zubel A, Celik I, Rougier P, Ciardiello F: Cetuximab plus irinotecan, fluorouracil, and leucovorin as first-line treatment for metastatic colorectal cancer: updated analysis of overall survival according to tumor KRAS and BRAF mutation status. J Clin Oncol 2011;29:2011-2019.

-8 Folprecht G, Gruenberger T, Bechstein WO, Raab HR, Lordick F, Hartmann JT, Lang H, Frilling A, Stoehlmacher J, Weitz J, Konopke R, Stroszczynski C, Liersch T, Ockert D, Herrmann T, Goekkurt E, Parisi F, Köhne CH: Tumour response and secondary resectability of colorectal liver metastases following neoadjuvant chemotherapy with cetuximab: the CELIM randomised phase 2 trial. Lancet Oncol 2010;11:38-47.

-9 Emmert M, Pohl-Dernick K, Wein A, Dörje F, Merkel S, Boxberger F, Männlein G, Joost R, Harich H-D, Thiemann R, Lamberti C, Neurath MF, Hohenberger W, Schöffski O: Palliative treatment of colorectal cancer in Germany: cost of care and quality of life. Eur J Health Econ 2013;14:629-638.

-10 Wein A, Riedel C, Brückl W, Merkel S, Ott R, Hanke B, Baum U, Fuchs F, Günther K, Reck T, Papadopoulos T, Hahn EG, Hohenberger W: Neoadjuvant treatment with weekly high-dose 5-Fluorouracil as 24-hour infusion, folinic acid and oxaliplatin in patients with primary resectable liver metastases of colorectal cancer. Oncology 2003;64:131-138.

-11 Wein A, Riedel C, Köckerling F, Martus P, Baum U, Brueckl WM, Reck T, Ott R, Hänsler J, Bernatik T, Becker D, Schneider T, Hohenberger W, Hahn EG: Impact of surgery on survival in palliative patients with metastatic colorectal cancer after first line treatment with weekly 24-hour infusion of high-dose 5-fluorouracil and folinic acid. Ann Oncol 2001;12:1721-1727.

-12 Therasse P, Arbuck SG, Eisenhauer EA, Wanders J, Kaplan RS, Rubinstein L, Verweij J, Van Glabbeke M, van Oosterom AT, Christian MC, Gwyther SG: New guidelines to evaluate the response to treatment in solid tumors. European Organization for Research and Treatment of Cancer, National Cancer Institute of the United States, National Cancer Institute of Canada. J Natl Cancer Inst 2000;92:205-216.

13 DCTD N, NIH, DHHS (1999): Cancer Therapy Evaluation Program Common Toxicity Criteria, version 2.0.

14 Greenwood M: The Natural Duration of Cancer. Reports on Public Health and Medical Subjects, 33. London, Her Majesty's Stationary Office, 1926.

15 Arnold D, Schmoll HJ, Lang H, Knoefel WT, Ridwelski K, Trarbach T, Staib L, Kirchner T, Geissler M, Seufferlein T, Amthauer H, Riess H, Schlitt HJ, Piso P: Specific treatment situations in metastatic colorectal cancer (in German). Onkologie 2010;33(suppl 4):8-18.

16 Watkins DJ, Chau I, Cunningham D, Mudan SS, Karanjia N, Brown G, Ashley S, Norman AR, Gillbanks A: Defining patient outcomes in stage IV colorectal cancer: a prospective study with baseline stratification according to disease resectability status. Br J Cancer 2010;102:255-261.

17 Fuchs CS, Marshall J, Mitchell E, Wierzbicki R, Ganju V, Jeffery M, Schulz J, Richards D, Soufi-Mahjoubi R, Wang B, Barrueco J: Randomized, controlled trial of irinotecan plus infusional, bolus, or oral fluoropyrimidines in first-line treatment of metastatic colorectal cancer: results from the BICC-C Study. J Clin Oncol 2007;25:4779-4786.

-18 Goldberg RM, Sargent DJ, Morton RF, Fuchs CS, Ramanathan RK, Williamson SK, Findlay BP, Pitot HC, Alberts SR: A randomized controlled trial of fluorouracil plus leucovorin, irinotecan, and oxaliplatin combinations in patients with previously untreated metastatic colorectal cancer. J Clin Oncol 2004;22:23-30.

$>19$ Tournigand C, Cervantes A, Figer A, Lledo G, Flesch M, Buyse M, Mineur L, Carola E, Etienne PL, Rivera F, Chirivella I, Perez-Staub N, Louvet C, André T, Tabah-Fisch I, de Gramont A: OPTIMOX1: a randomized study of FOLFOX4 or FOLFOX7 with oxaliplatin in a stop-and-Go fashion in advanced colorectal cancer - a GERCOR study. J Clin Oncol 2006;24:394-400.

-20 Tournigand C, André T, Achille E, Lledo G, Flesh M, Mery-Mignard D, Quinaux E, Couteau C, Buyse M, Ganem G, Landi B, Colin P, Louvet C, de Gramont A: FOLFIRI followed by FOLFOX6 or the reverse sequence in advanced colorectal cancer: a randomized GERCOR study. J Clin Oncol 2004;22:229-237.

-21 Colucci G, Gebbia V, Paoletti G, Giuliani F, Caruso M, Gebbia N, Cartenì G, Agostara B, Pezzella G, Manzione L, Borsellino N, Misino A, Romito S, Durini E, Cordio S, Di Seri M, Lopez M, Maiello E, Montemurro S, Cramarossa A, Lorusso V, Di Bisceglie M, Chiarenza M, Valerio MR, Guida T, Leonardi V, Pisconti S, Rosati G, Carrozza F, Nettis G, Valdesi M, Filippelli G, Fortunato S, Mancarella S, Brunetti C; Gruppo Oncologico Dell'Italia Meridionale: Phase III randomized trial of FOLFIRI versus FOLFOX4 in the treatment of advanced colorectal cancer: a multicenter study of the Gruppo Oncologico Dell'Italia Meridionale. J Clin Oncol 2005;23:4866-4875.

-22 Sargent DJ, Köhne C-H, Sanoff HK, Bot BM, Seymour MT, de Gramont A, Porschen R, Saltz LB, Rougier P, Tournigand C, Douillard JY, Stephens RJ, Grothey A, Goldberg RM: Pooled safety and efficacy analysis examining the effect of performance status on outcomes in nine first-line treatment trials using individual data from patients with metastatic colorectal cancer. J Clin Oncol 2009;27:1948-1955. 


\section{Oncology}

\begin{tabular}{l|l}
\hline Oncology 2015;88:103-121 \\
\hline DOI: 10.1159/000368246 & $\begin{array}{l}\text { @ 2014 S. Karger AG, Basel } \\
\text { www.karger.com/ocl }\end{array}$ \\
\hline
\end{tabular}

Wein et al.: Palliative Treatment of Colorectal Cancer with Secondary Metastasis Resection in Germany

23 Falcone A, Ricci S, Brunetti I, Pfanner E, Allegrini G, Barbara C, Crinò L, Benedetti G, Evangelista W, Fanchini L, Cortesi E, Picone V, Vitello S, Chiara S, Granetto C, Porcile G, Fioretto L, Orlandini C, Andreuccetti M, Masi G; Gruppo Oncologico Nord Ovest: Phase III trial of infusional fluorouracil, leucovorin, oxaliplatin, and irinotecan (FOLFOXIRI) compared with infusional fluorouracil, leucovorin, and irinotecan (FOLFIRI) as first-line treatment for metastatic colorectal cancer: the Gruppo Oncologico Nord Ovest. J Clin Oncol 2007;25:16701676.

24 Bennouna J, Sastre J, Arnold D, Osterlund P, Greil R, Van Cutsem E, von Moos R, Viéitez JM, Bouché O, Borg C, Steffens CC, Alonso-Orduña V, Schlichting C, Reyes-Rivera I, Bendahmane B, André T, Kubicka S; ML18147 Study Investigators: Continuation of bevacizumab after first progression in metastatic colorectal cancer (ML18147): a randomised phase 3 trial. Lancet Oncol 2013;14:29-37.

25 Köhne CH, van Cutsem J, Wils J, Bokemeyer C, El-Serafi M, Lutz MP, Lorenz M, Reichardt P, Rückle-Lanz H, Frickhofen N, Fuchs R, Mergenthaler HG, Langenbuch T, Vanhoefer U, Rougier P, Voigtmann R, Müller L, Genicot B, Anak O, Nordlinger B; European Organisation for Research and Treatment of Cancer Gastrointestinal Group: Phase III study of weekly high-dose infusional fluorouracil plus folinic acid with or without irinotecan in patients with metastatic colorectal cancer: European Organisation for Research and Treatment of Cancer Gastrointestinal Group Study 40986. J Clin Oncol 2005;23:4856-4865.

26 Wein A, Boxberger F, Siebler J, Wolff K, Ostermeier N, Busse D, Maennlein G, Hohenberger W, Neurath MF, Hofheinz R: Efficacy and toxicity of second-line AIO plus irinotecan (IRI) after pre-treatment with AIO plus oxaliplatin (L-OHP) in the sequential therapy of metastatic colorectal cancer (CRC). J Clin Oncol 2013;31(suppl abstr 3561).

27 Albrecht H, Boxberger F, Wolff K, Ostermeier N, Reulbach U, Maennlein G, Meyer T, Hohenberger W, Hahn EG, Wein A: Palliative first-line treatment with weekly high-dose 5-fluorouracil and sodium folinic acid (s-FA) (AIO-schedule) as $24 \mathrm{~h}$-infusion plus biweekly oxaliplatin (ox) in patients with definitively non-resectable metastatic colorectal cancer (CRC) following secondary (sec.) metastatic resection: an interdisciplinary phase II trial. J Clin Oncol 2009;27 (abstr 31471).

28 Chibaudel B, Bonnetain F, Tournigand C, Bengrine-Lefevre L, Teixeira L, Artru P, Desramé J, Larsen AK, André T, Louvet C, de Gramont A: Simplified prognostic model in patients with oxaliplatin-based or irinotecan-based first-line chemotherapy for metastatic colorectal cancer: a GERCOR study. Oncologist 2011;16:1228-1238.

29 Dy GK, Krook JE, Green EM, Sargent DJ, Delaunoit T, Morton RF, Fuchs CS, Ramanathan RK, Williamson SK, Findlay BP, Pockaj BA, Sticca RP, Alberts SR, Pitot HC IV, Goldberg RM; Intergroup N9741: Impact of complete response to chemotherapy on overall survival in advanced colorectal cancer: results from Intergroup N9741. J Clin Oncol 2007;25:3469-3474.

-30 Bismuth H, Adam R, Lévi F, Farabos C, Waechter F, Castaing D, Majno P, Engerran L: Resection of nonresectable liver metastases from colorectal cancer after neoadjuvant chemotherapy. Ann Surg 1996;224:509-520.

-31 Van Cutsem E, Tabernero J, Lakomy R, Prenen H, Prausová J, Maraculla T, Ruff P, van Hazel GA, Moiseyenko V, Ferry D, McKendrick J, PolikoffJ, Tellier A, Castan R, Allegra C: Addition of aflibercept to fluorouracil, leucovorin, and irinotecan improves survival in a phase III randomized trial in patients with metastatic colorectal cancer previously treated with an oxaliplatin-based regimen. J Clin Oncol 2012;30:3499-3506.

-32 Folprecht G, Grothey A, Alberts S, Raab HR, Köhne CH: Neoadjuvant treatment of unresectable colorectal liver metastases: correlation between tumour response and resection rates. Ann Oncol 2005;16:1311-1319.

-33 Elias D, Lefevre JH, Chevalier J, Brouquet A, Marchal F, Classe JM, Ferron G, Guilloit JM, Meeus P, Goéré D, Bonastre J: Complete cytoreductive surgery plus intraperitoneal chemohyperthermia with oxaliplatin for peritoneal carcinomatosis of colorectal origin. J Clin Oncol 2009;27:681-685.

34 Ruers T, Punt C, Van Coevorden F, Pierie JP, Borel-Rinkes I, Ledermann JA, Poston G, Bechstein W, Lentz MA, Mauer M, Van Cutsem E, Lutz MP, Nordlinger B; EORTC Gastro-Intestinal Tract Cancer Group, Arbeitsgruppe Lebermetastasen und -tumoren in der Chirurgischen Arbeitsgemeinschaft Onkologie (ALM-CAO) and the National Cancer Research Institute Colorectal Clinical Study Group (NCRI CCSG): Radiofrequency ablation combined with systemic treatment versus systemic treatment alone in patients with non-resectable colorectal liver metastases: a randomized EORTC Intergroup phase II study (EORTC 40004). Ann Oncol 2012;23:26192626.

-35 Kopetz S, Chang GJ, Overman MJ, Eng C, Sargent DJ, Larson DW, Grothey A, Vauthey JN, Nagorney DM, McWilliams RR: Improved survival in metastatic colorectal cancer is associated with adoption of hepatic resection and improved chemotherapy. J Clin Oncol 2009;27:3677-3683.

-36 Kriza C, Emmert M, Wahlster P, Niederländer C, Kolominsky-Rabas P: Cost of illness in colorectal cancer: an international review. Pharmacoeconomics 2013;31:577-588.

-37 Clerc L, Jooste V, Lejeune C, Schmitt B, Arveux P, Quantin C, Faivre J, Bouvier AM: Cost of care of colorectal cancers according to health care patterns and stage at diagnosis in France. Eur J Health Econ 2008;9:361-367.

-38 Grothey A, Van Cutsem E, Sobrero A, Siena S, Falcone A, Ychou M, Humblet Y, Bouché O, Mineur L, Barone C, Adenis A, Tabernero J, Yoshino T, Lenz HJ, Goldberg RM, Sargent DJ, Cihon F, Cupit L, Wagner A, Laurent D; CORRECT Study Group: Regorafenib monotherapy for previously treated metastatic colorectal cancer (CORRECT): an international, multicentre, randomised, placebo-controlled, phase 3 trial. Lancet 2013;381: 303-312. 